\title{
肿瘤微环境刺激响应型上转换光动力诊疗体系的构建和发展
}

\author{
间涛 ${ }^{a}$ 刘振华 $b$ 宋昕玥*,a 张书圣*, $a$ \\ ( ${ }^{a}$ 临沂大学 化学化工学院 山东省肿瘤标志物检测技术重点实验室 临沂 276005) \\ ( ${ }^{b}$ 山东师范大学 化学化工与材料科学学院 济南 250014)
}

\begin{abstract}
摘要 光动力治疗是一种新型的非侵入式肿瘤治疗方法, 具有创伤性和毒性小、选择性好、无耐药性、可重复治疗等 突出优点, 在癌症的治疗上取得了显著的成效. 为了增加光动力治疗的组织穿透深度, 研究者提出构建基于上转换纳 米颗粒(upconversion nanoparticles, UCNPs)的光动力诊疗探针(简称上转换光动力诊疗探针). 基于发光共振能量转移过 程, 上转换光动力诊疗探针利用 UCNPs 在近红外光激发下发射的荧光激活负载的光敏剂发挥光动力疗效, 有助于实 现深层肿瘤的治疗. 新型的上转换光动力诊疗探针通过多功能一体化的结构组合设计可以实现靶向运输、成像诊断以 及刺激响应的按需治疗, 是未来纳米医药发展的必然趋势. 目前, 研究者越来越关注构建基于肿瘤微环境刺激响应型 上转换光动力诊疗体系, 以提高治疗体系的靶向性, 改善光动力治疗效果, 并减小对周围正常组织的毒性. 本工作主 要讨论了基于 $\mathrm{pH}$ 、酶及过氧化氢刺激响应型上转换光动力诊疗体系的构建和发展, 并对其发展前景进行了展望. 关键词 光动力治疗; 上转换纳米颗粒; 肿瘤微环境; 刺激响应; 诊疗一体化
\end{abstract}

\section{Construction and Development of Tumor Microenvironment Stimulus-Responsive Upconversion Photodynamic Diagnosis and Treatment System}

\author{
Yan, Tao $^{a} \quad$ Liu, Zhenhua ${ }^{b} \quad$ Song, Xinyue ${ }^{*, a} \quad$ Zhang, Shusheng*,a \\ ( ${ }^{a}$ Shandong Provincial Key Laboratory of Detection Technology for Tumor Markers, College of Chemistry and \\ Chemical Engineering, Linyi University, Linyi 276005, China) \\ $\left({ }^{b}\right.$ College of Chemistry, Chemical Engineering and Materials Science, Shandong Normal University, Jinan 250014)
}

\begin{abstract}
Photodynamic therapy (PDT) is a new type of non-invasive tumor therapy, which has the advantages of less trauma and toxicity, good selectivity, no drug resistance and repeatable treatment. Thus, PDT has achieved remarkable results in the treatment of cancer. In order to increase its depth of tissue penetration, researchers proposed to build novel PDT nanotheranostic systems based on upconversion nanoparticles (referred as upconversion photodynamic nanotheranostic system). Based on the luminescence resonance energy transfer process, upconversion photodynamic nanotheranostic systems use the emitted fluorescence of upconversion nanoparticles which is excited by the near-infrared laser to further excite the loaded photosensitizer, thus it is advantageous to the treatment of deep tumors. Via the multi-functional structure design, the newly developed upconversion photodynamic nanotheranostic agent could achieve the targeted transportation, imaging diagnosis and stimulation response for the achievement of on-demand treatment, which is the trend for the development of nanomedicine in the future. At present, researchers pay more and more attention to the construction of tumor microenvironment responsive nanotheranostic system, in order to improve the targeting to the tumor section, improve the PDT efficacy, and reduce the toxicity to the surrounding normal tissues. This work mainly discusses the construction and development of upconversion nanotheranostic systems based on the stimulation of $\mathrm{pH}$, enzyme and hydrogen peroxide. In addition, we prospect its development in the future.
\end{abstract}

Keywords photodynamic therapy; upconversion nanoparticles; tumor microenvironment; stimulation response; theranostic

\section{1 引言}

癌症起病隐匿, 进展迅速, 迫使人们不断探索更为 有效的肿瘤诊疗策略. 目前, 临床治疗癌症方法有手术 切除、放疗、化疗等, 但治疗效果有待提高. 基于材料
学、生物学、化学和医学等多学科交叉诞生的癌症纳米 诊疗体系，通过集成多功能的结构组合设计，实现了对 癌症的成像诊断、药物靶向运输和刺激响应的按需治疗, 成为未来医药发展的必然趋势. 光动力治疗 (Photodynamic therapy, PDT) 利用光敏剂在特定波长的

*E-mail: songxinyue428@163.com; shushzhang@126.com; Tel.: 0539-7258627

Received April 29, 2020; published June 15, 2020.

Project supported by the National Natural Science Foundation of China (No. 21775063), the Nature Science Foundation of Shandong Province (No. ZR2018ZC0231) and the Key Research Plan of Shandong Province (No. 2017GGX40110).

项目受国家自然科学基金(No. 21775063)、山东省自然科学基金(No. ZR2018ZC0231)和山东省重点研发计划(No. 2017GGX40110)资助. 
激光照射下跃迁至激发态, 进而与组织周围的氧气等发 生反应生成活性氧(Reactive oxygen species, ROSs), 诱 导细胞死亡. 上转换纳米颗粒(Upconversion nanoparticles, UCNPs) 能够在组织穿透能力强的近红外光 (Near infrared light, NIR)激发下, 发射紫外-可见光区或近红 外区苂光. 为了增加 PDT 的组织穿透深度, 研究者提出 构建基于 UCNPs 的光动力诊疗探针(简称上转换光动力 诊疗探针). 相比于可见光, NIR 对组织的穿透深度可达 到厘米级. 因此, 上转换光动力诊疗探针利用 UCNPs 在 NIR 激发下的发射光通过发光共振能量转移(Luminescence resonance energy transfer, LRET)过程激活负载的 光敏剂发挥光动力疗效, 有助于实现深层肿瘤的治疗. 上转换光动力诊疗探针还能够有效地改善传统光动力 诊疗中光敏剂难运输和难靶向等缺点, 实现直接杀死癌 细胞或摧毁肿瘤部位血管及激活宿主免疫系统的目的. 因此, 上转换光动力诊疗探针引起研究工作者的极大兴 趣. 为实现刺激响应的按需治疗, 研究者越来越关注构 建基于肿瘤微环境刺激响应型上转换光动力诊疗体系. 本工作讨论了 UCNPs、无机和有机光敏剂以及肿瘤微环 境刺激响应型上转换光动力诊疗体系的构建和发展, 并 对其未来发展前景进行了展望.

\section{2 上转换纳米颗粒}

上转换光动力诊疗探针主要由四种组分组成, 即成 像剂(UCNPs)、治疗剂(有机光敏剂和无机光敏剂等)、 载体(聚合物、二氧化硅、石墨烯等)和表面改性剂(聚合 物、靶向分子、刺激响应分子阀等).

UCNPs 主要由氧化物、氟化物或卤氧化物等基质掺 杂三价稀土离子构成 ${ }^{[1]}$. 上转换发光(Upconversion luminescence, UCL)过程主要是通过吸收两个或多个低能 光子跃迁至激发态, 然后辐射出一个高能光子. 常用机 制为激发态吸收(Excited state absorption, ESA), 能量传 递上转换(Energy transfer upconversion, ETU)和光子雪 崩(Photon avalanche, PA). 由于这一过程违背斯托克斯 (Stokes) 定律, 因此又被称为 “反-斯托克斯发光” (Anti-Stokes luminescence) ${ }^{[2,3]}$. 作为一种新型的荧光纳 米材料, UCNPs 可在长波长的 NIR 激发下, 经上转换发 光过程发射出短波长的紫外-可见区或近红外区荧光. UCNPs 凭借其四大主要优点在生物医学领域发挥着重 要的应用: (1) UCNPs 激发波长(常用 $808 \mathrm{~nm}$ 和 $980 \mathrm{~nm}$ ) 正好位于 “光学透明窗口” $(660 \sim 1100 \mathrm{~nm})^{[4]}$, 具有理想 的生物组织穿透深度和较低的生物组织损伤. NIR 还具 有较低的自体苂光背景、较高的信噪比和良好的检测灵 敏度 ${ }^{[5]}$. (2) 在 NIR 激发下, 通过改变 UCNPs 的基质种 类或掺杂稀土离子浓度可以精确调节其发射谱带, 这对 多色生物菼光成像及生物分子检测具有重要的应用价 值 ${ }^{[6,7]}$. (3) 钝离子 $\left(\mathrm{Gd}^{3+}\right)$ 掺杂的 UCNPs 表现出协同的磁 学及光学特性, 可制备多模式成像探针实现上转换荧光
成像和磁共振成像(Magnetic resonance imaging, MRI); 此外, 引入放射性元素如 ${ }^{18} \mathrm{~F}$ 等, 可以实现正电子发射 型计算机断层成像(Positron emission computed tomography, PET $)^{[8]}$. (4) 毒性研究结果表明 UCNPs 具有良好 的生物相容性, 没有明显的细胞及活体生物毒性 ${ }^{[9]}$. 因 此, UCNPs 作为成像探针和载体被广泛应用于肿瘤的诊 疗一体化中, 主要集中在生物成像指导的化学药物治 疗、PDT、光热疗法、化学联合疗法、基因治疗和免疫 治疗及体外诊断等方面. 本综述主要关注上转换纳米颗 粒在 PDT 中的应用和进展.

\section{3 光动力治疗}

光动力过程中包括 3 个基本要素: 特定波长的光、 光敏剂和组织周围的氧气分子等生物物质 ${ }^{[10]}$. 与临床 化疗和放疗相比, PDT 具有创伤性和毒性小、选择性好、 无耐药性、可重复治疗等突出优点, 被成功应用于皮肤、 头颈部、食管、胰腺和膀胱等浅层及脏器的肿瘤治疗 中 ${ }^{[10,11]}$. 然而, 临床上常用的光敏剂其激发光多处于可 见光区，受生物组织的光吸收和散射的影响，对生物组 织的穿透能力差, 限制其治疗能力. UCNPs 作为光敏剂 的载体为解决这一问题提供了新的策略. UCNPs 的激发 光处于近红外区, 具有更深的组织穿透能力, 能够通过 LRET 过程有效地激发光敏剂, 产生强活性的 ROSs, 同 时改善光敏剂分子在生物体内递送困难、靶向性低等问 题, 实现直接杀死癌细胞或摧毁肿瘤部位血管及激活宿 主免疫系统等目的 ${ }^{[12]}$.

2007 年, Zhang 等 ${ }^{[13]}$ 首次提出上转换光动力治疗概 念, 并通过人类乳癌细胞验证了上转换光动力治疗效 果. 2011 年, Liu 等 ${ }^{[14]}$ 首次在活体水平证实基于 UCNPs 构建的光动力治疗体系能有效抑制肿瘤生长. 自此, 上 转换光动力诊疗体系引起了研究者广泛的研究兴趣.

\section{1 光敏剂}

目前, 常用的光敏剂包含有机光敏剂和无机光敏 剂. 光敏剂主要通过类型 I (Type I) 和类型 II (Type II)发 挥光敏活性, 产生 ROSs. 如图 1 所示, 用一定波长的激 光照射光敏剂, 光敏剂吸收光子后由基态跃迁至单重激 发态. 处于激发态的光敏剂十分不稳定, 可以通过辐射 或者非辐射跃迁的方式回到基态，也可以通过系间窝越 生成更为稳定的三重激发态. Type I 以产生羟基自由基 为主. 三重激发态光敏剂直接与细胞微环境中生物分子 相互作用, 捕获氢原子或电子形成自由基. 其中带负电 的自由基和氧气发生电子转移作用，生成超氧自由基阴 离子, 进而通过歧化作用或单电子还原过程产生羟基自 由基; Type II 以产生单线态氧为主. 三重激发态光敏剂 与组织周围的基态氧 $\left({ }^{3} \mathrm{O}_{2}\right)$ 发生反应，将能量传递给后者 以生成单线态氧 ${ }^{[15]}$. 


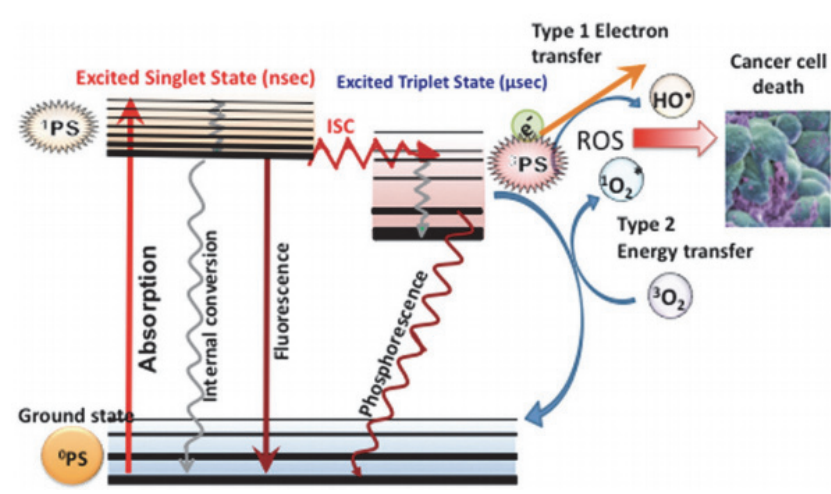

图 1 类型 I (Type I) 和类型 II (Type II)光敏剂的作用机理示意图 ${ }^{[15]}$ Figure 1 Schematic diagram of function mechanism for Type I and Type II photosensitizers ${ }^{[15]}$

\section{1 .1 有机光敏剂}

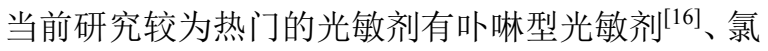
型光敏剂、酞菁型光敏剂 ${ }^{[17]}$ 以及 BODIPY 型光敏剂 ${ }^{[18]}$. Peng 等 ${ }^{[17]}$ 系统介绍了近年来靶向性酞菁型光敏剂的研 究进展, 并对其未来重点研究方向做出了展望. Meng 等 ${ }^{[18]}$ 详细介绍并系统评价了 BODIPY 及其衍生物作为 光敏剂在肿瘤诊疗中的治疗效果和应用.

在上转换光动力诊疗体系中, 常用的有机光敏剂包 括锌酞菁 (Zinc phthalocyanine, ZnPc)、部花青 540 (Merocyanine 540, MC540)、血卟啉(Hematoporphyri, $\mathrm{HP}) 、$ 四苯基卟啉 $(5,10,15,20$-tetraphenylporphyrin, TPP)、 亚甲基蓝(Methylene blue, MB), 玫瑰红(Rose bengal, RB), 二氢卟吩 e6 (Chlorin e6, Ce6), 铝酞菁(Aluminum phthalocyanine chloride)、二羟基硅酞菁(Silicon phthalocyanine dihydroxide, SPCD) 等. 在特定波长的光激发 下，有机光敏剂主要通过 type II 参与 PDT 过程.

\section{1 .2 无机光敏剂}

与有机 PS 相比, 无机光敏剂在生物体内的作用时 间更长、更稳定. 半导体无机材料如二氧化钛 $\left(\mathrm{TiO}_{2}\right)$ 、 石墨碳氮化物 $\left(\mathrm{g}-\mathrm{C}_{3} \mathrm{~N}_{4}\right)$, 氧化锌 $(\mathrm{ZnO}) 、$ 黑磷和富勒烯等. 半导体无机材料主要发生 type I -光动力过程.

g- $\mathrm{C}_{3} \mathrm{~N}_{4}$ 纳米材料具有相对窄的带隙 $(2.7 \mathrm{eV})$, 可以 在紫外-可见区的光激发下生成活性自由基. 2016 年, Lin 等 ${ }^{[19]}$ 通过模板蚀刻工艺制备 $808 \mathrm{~nm}$ 激光激活的上 转换光动力诊疗体系 UCNPs@g-C $\mathrm{C}_{3} \mathrm{~N}_{4}$-PEG. UCNPs 在 $808 \mathrm{~nm}$ 激发光下发射的紫外-可见光能够有效地激发 g- $\mathrm{C}_{3} \mathrm{~N}_{4}$ 产生大量的 ROSs 以用于 PDT. UCNPs 中 $\mathrm{Nd}^{3+}$ 还 能够引起光热治疗效应，协同抑制肿瘤生长.

最近, g- $\mathrm{C}_{3} \mathrm{~N}_{4}$ 量子点也可以通过阳性聚合物如聚 $L$ 赖氨酸修饰到 UCNPs 表面, 构建上转换光动力诊疗体 系 ${ }^{[20]}$. 研究表明, 合成的 $\mathrm{g}-\mathrm{C}_{3} \mathrm{~N}_{4}$ 量子点不仅可以作为无 机光敏剂, 还可以实现苂光成像.

金属有机框架(Metal-organic frameworks, MOFs)是 一类有序、多孔的晶态材料, 具有比表面积大、结构可 设计性强、易生物降解等独特优势. 基于 MOFs 构建的
纳米药物载体已经在肿瘤的化疗、PDT、光热治疗、免 疫治疗以及联合治疗等基础研究得到不断发展.

Zhang 等 ${ }^{[21]}$ 详细介绍了基于 MOFs 构建的生物功能 化材料在肿瘤治疗中的应用, 并对其在生物医学领域的 应用进行了展望. 研究结果表明, MOFs 可通过选择性 各向异性作用成功生长在 UCNPs 表面 ${ }^{[22]}$. 基于 UCNPs 到 MOFs 间直接共振能量转移, 具有异质结构的 UCNPs@MOFs 能够在 NIR 照射下产生 ROSs. 此外, MOFs 的多孔通道可有效地负载化疗药物, 实现化疗治 疗和 NIR 诱导的 PDT 协同作用 ${ }^{[23,24]}$.

\subsection{3 光敏剂的负载方式}

光敏剂的负载方式会影响上转换光动力诊疗体系 的性能和治疗效果. UCNPs 通过 LRET 过程激发光敏剂 分子. 因此, 必须满足 UCNPs 的发射光与光敏剂 (photosensitizer, PS) 的吸收光具有良好的光谱匹配, 且 两者处于有效距离内(通常应小于 $10 \mathrm{~nm}$ ).

为了增加 PDT 效果, 缩短 UCNPs 与光敏剂间的共 振能量转移距离, 我们课题组创新性地制备了超薄硅层 包覆的 UCNPs $\left(\mathrm{UCNPs} @ \mathrm{SiO}_{2}\right)$, 将负载光敏剂的硅层厚 度控制在 $7.5 \sim 9.0 \mathrm{~nm}$ 间, 极大地缩短了能量供体 (UCNPs)和能量受体(光敏剂, 亚甲基蓝)间的能量转移 距离, 提高了 PDT 的疗效 ${ }^{[25]}$.

为了进一步缩短 LRET 的距离, 我们组合成了三明 治式 UCNPs, 将两种发光离子 $\mathrm{Tm}^{3+}$ 和 $\mathrm{Ho}^{3+}$ 控制在厚度 约为 $2.0 \mathrm{~nm}$ 的中间层中, 表面包覆厚度为 $8.5 \sim 10.6 \mathrm{~nm}$ 的硅层, 进一步缩短发光层与光敏剂间的 LRET 距离 (如图 2 所示). 此外, UCNPs 发射多种荧光, 可以同时激 发两种光敏剂, 增加 ROSs 的产生量. 在线粒体靶向基 团的驱动下, 制备的 UCNPs 光动力诊疗探针可以选择 性地富集于线粒体中，在 NIR 刺激下，原位产生 ROSs, 引起癌细胞线粒体调节的细胞调亡. 制备的上转换光动 力诊疗探针可以极大地诱导癌细胞调亡(调亡率高达 $79 \%$ ), 并有效抑制肿瘤组织的生长(肿瘤体积减小至 $36 \%)^{[26]}$.

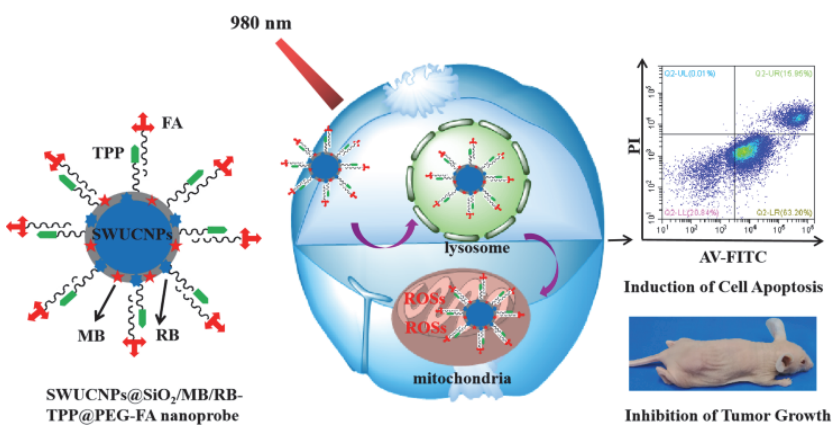

图 2 三明治式 UCNPs 负载两种光敏剂实现肿瘤细胞线粒体靶向 PDT, 诱导细胞凋亡并抑制肿瘤生长 ${ }^{[26]}$

Figure 2 Sandwich-structured UCNPs loading dual photosensitizer molecules to achieve mitochondria-targeted photodynamic therapy for the induction of cancer cells apoptosis and inhibition of the tumor growth ${ }^{[26]}$ 
光敏剂的负载方式对 PDT 效率有重要影响. 研究 前期, 光敏剂大多通过物理吸附的方式负载于纳米载体 上. 然而, 物理吸附方式易导致光敏剂泄漏, 引起 LRET 效率和 PDT 效果降低, 同时容易导致全身毒副作 用. 而基于共价键方式的上转换光动力治疗体系可以有 效地避免光敏剂的泄漏.

Kong 等 ${ }^{[27]}$ 将光敏剂玫瑰红通过氨基与羧基间的缩 合反应修饰于 UCNPs 表面, 构建上转换光动力诊疗体 系. Giri 等 ${ }^{[28]}$ 利用氨基与羧基间的缩合反应将光敏剂玫 瑰红修饰于 $O$-磷酸乙醇胺功能化 UCNPs 表面, 然后进 一步修饰介孔二氧化硅层以负载抗癌药物. Horák 等 ${ }^{[2]]}$ 也利用氨基与羧基间的缩合反应将羧基酞菁铝( $\mathrm{Al}$ carboxyphthalocyanine, Al Pc-COOH)共价修饰于聚乙烯亚 胺 (Polyethyleneimine, PEI) 功能化的二氧化硅包裹 UCNPs 表面. Zhang 等 ${ }^{[30]}$ 利用四嗪与烯烃基间点击反应 将功能化光敏剂玫瑰红共价修饰于 UCNPs 表面, 实现 PDT 的 “关闭” 状态向 “开启” 状态的转变. 相比较于 物理负载方式, 共价键负载能够有效解决光敏剂泄漏的 问题, 但需要光敏剂具有特殊化学基团, 且负载工艺较 为繁琐、耗时.

\section{4 肿瘤微环境刺激响应型上转换光动力诊疗体 系的构建和发展}

由于自身的快速生长和转移, 肿瘤细胞引起了一些 基质的变化, 形成不同于正常组织的细胞微环境, 比如 乏氧环境、微酸性、高还原电势和过表达或特异性表达 的酶 ${ }^{[31]}$. 研究工作者基于肿瘤微环境构建和发展了新 型的刺激响应型光动力诊疗体系, 以提高诊疗体系对肿 瘤组织的靶向性, 减小对正常组织的毒副性 ${ }^{[32]}$. 本综述 主要介绍刺激响应型上转换光动力诊疗体系的构建和 在肿瘤诊疗一体化中的应用.

\section{$4.1 \mathrm{pH}$ 值敏感型上转换光动力诊疗体系}

肿瘤生长和转移十分迅速, 肿瘤血管无法提供足够 的养料和氧气来供应肿瘤细胞的迅速繁殖. 因此, 肿瘤 细胞会发生一定的无氧糖酵解产生乳酸. 凭借细胞膜表 面活性质子泵, 酸性分泌物释放至细胞外液, 而肿瘤内 部血液速度减慢, 肿瘤组织难以恢复至中性而维持酸 性. 因此, 相对于正常生理组织 $\mathrm{pH}$ (7.2 7.4), 肿瘤组 织呈现出一定的弱酸性, $\mathrm{pH}$ 为 $6.5 \sim 7.2^{[33]}$. $\mathrm{pH}$ 值敏感型 上转换光动力诊疗体系主要是利用 $\mathrm{pH}$ 敏感材料在微酸 环境下, 电荷反转, 变为正电性, 利于进入细胞内, 或 $\mathrm{pH}$ 敏感型聚合物在酸性条件下由聚集状态变为游离状 态, 释放光敏剂, 或利用酸性敏感键在酸性刺激下断裂, 释放靶向基团, 实现靶向光动力治疗. 因此, $\mathrm{pH}$ 敏感型 上转换光动力诊疗探针被内吞入癌细胞后, 在内涵体 ( $\mathrm{pH}$ 为 $5.0 \sim 6.0$ ) 和溶酶体 $(\mathrm{pH}$ 为 $4.0 \sim 5.0$ ) 内将进一步加 强光动力治疗效果 ${ }^{[34]}$.
常用的 $\mathrm{pH}$ 敏感材料为聚丙烯酸(Polyacrylic acid, PAA)、DNA、多肽、焦脱镁叶绿酸 a (Pyropheophorbide a) 等. 常用的 $\mathrm{pH}$ 敏感键为缩醛键(Acetal bond)、肼键 (Hydrazine bond)、腙键(Hydrazone bond)、酯键(Ester bond)和苯并亚胺键(Benzoic imine bond) 等 ${ }^{[35]}$.

基于静电吸引的层层组装(Layer by layer, LBL)技 术能够赋予 UCNPs 良好的亲水性, 且具有可控涂层厚 度. Liu 课题组 ${ }^{[36]}$ 利用 LBL 技术构建了一种 $\mathrm{pH}$ 敏感型 上转换纳米诊疗试剂(如图 3 所示). 负电性聚丙烯酸通 过配体交换修饰于 UCNPs 表面. 然后, 利用 LBL 技术 将光敏剂 Ce6 修饰的聚合物(Poly(allylamine hydrochloride)-Ce6-succinic anhydride, PAH-Ce6-SA)和正电性聚 合物聚丙烯胺盐酸盐 (poly(allylamine hydrochloride, PAH)依次吸附于 UCNPs 表面. 最后, 在纳米材料的外 表面包裹一层包含二甲基马来酸酕官能团的聚合物 (2,3-dimethylmaleic anhydride-PAH-polyethylene glycol, DMMA-PAH-PEG). 该聚合物在 $\mathrm{pH} 7.4$ 下呈现负电性, 在 $\mathrm{pH} 6.8$ 下电荷反转, 变成正电性. 由于细胞膜有磷脂 双分子层构成，带有一定的负电荷，因此，正电性聚合 物包裹的上转换诊疗探针将具有与细胞膜更好的相容 性, 有利于其快速进入细胞. 本实验利用 $\mathrm{Mn}^{2+}$ 掺杂的 UCNPs 在 NIR 激发下发射的红色荧光, 激活光敏剂 $\mathrm{Ce} 6$, 并实现上转换发光成像. 光敏剂的负载量可以通 过调节 PAH/PAH-Ce6-SA 层的数量来控制. 这种灵活的 设计策略和简便的制备方法激发了人们对开发新的治 疗诊断纳米平台的极大兴趣. 然而，该诊疗探针在正常 组织 $\mathrm{pH} 7.4$ 条件下, NIR 激发时也能诱导约 $40 \%$ 的细胞 致死率.

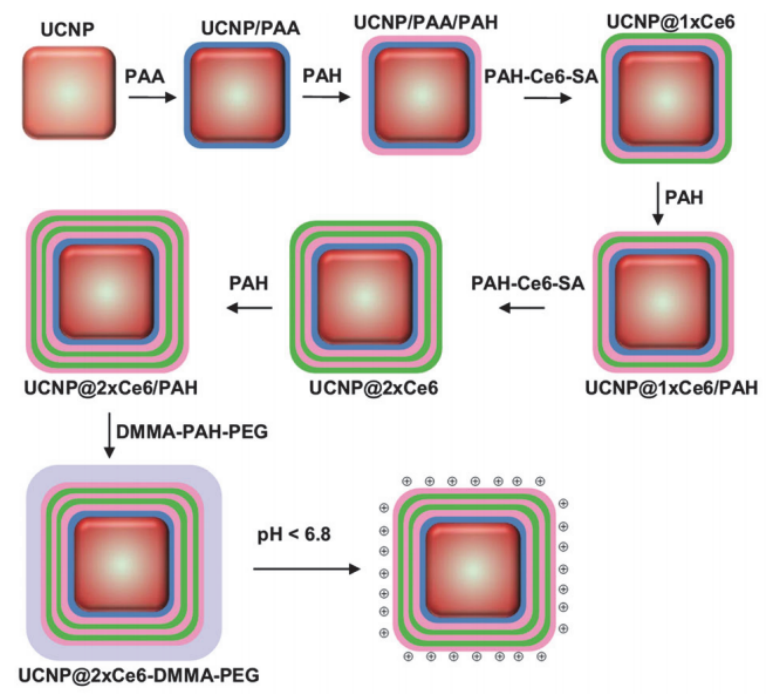

图 3 基于 $\mathrm{LBL}$ 策略的上转换光动力诊疗体系的设计 ${ }^{[36]}$

Figure 3 Design of the upconversion photodynamic nanotheranostic system based on the LBL strategy ${ }^{[36]}$

Chang 等 ${ }^{[37]}$ 利用聚合物修饰的脂质胶囊也构建了 $\mathrm{pH}$ 刺激响应的上转换光动力诊疗探针. 如图 4 所示, 该 课题组利用化学反应将光敏剂 RB 共价修饰于聚合物 
PEG-DAO 支链上, 然后包覆于 UCNPs 表面, 构建光动 力诊疗探针. 该探针表面修饰的 PEG 层能够有效增强 其在血液循环中的稳定性. 在肿瘤的微酸环境中, 该诊 疗探针表面的 PEG 游离, 暴露出叶酸分子, 靶向进入肿 瘤细胞内. 在 NIR 照射下, UCNPs 激活光敏剂 RB, 产生 ROSs. 因此, 该工作利用 $\mathrm{pH}$ 敏感型材料构建肿瘤微酸 环境靶向型上转换光动力诊疗探针.

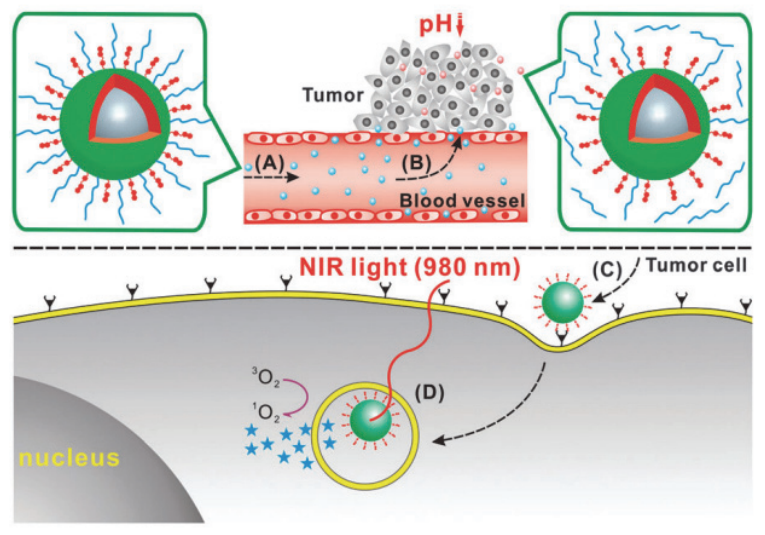

图 4 利用聚合物修饰的脂质胶囊构建肿瘤微酸环境靶向型上转换光 动力诊疗探针的示意图 ${ }^{[37]}$

Figure 4 Diagram of tumor acidic microenvironment targeted upconversion photodynamic nanotheranostic probe based on polymer modified lipid vesicles ${ }^{[37]}$

Gao 等 ${ }^{[38]}$ 利用具有聚集诱导增强的光敏剂、聚合物 单体和线粒体靶向基团三苯基膦(triphenylphosphine, TPP)构建新型的聚合物 PAIE-TPP, 并与 UCNPs 自组装 形成纳米颗粒. 进一步, 在该纳米颗粒外表面通过 $\mathrm{pH}$ 敏感的苯并亚胺键修饰 PEG 链, 构建 UCNPs@PAIETPP-PEG 光动力诊疗探针. 如图 5 所示, 该光动力诊疗 探针在肿瘤的微酸环境刺激下, 苯并亚胺键断裂, 表面 的 PEG 层游离, 暴露线粒体靶向基团 TPP. 在近红外光 刺激下, 富集于线粒体的探针原位产生 ROSs, 诱导线 粒体调节的细胞调亡.
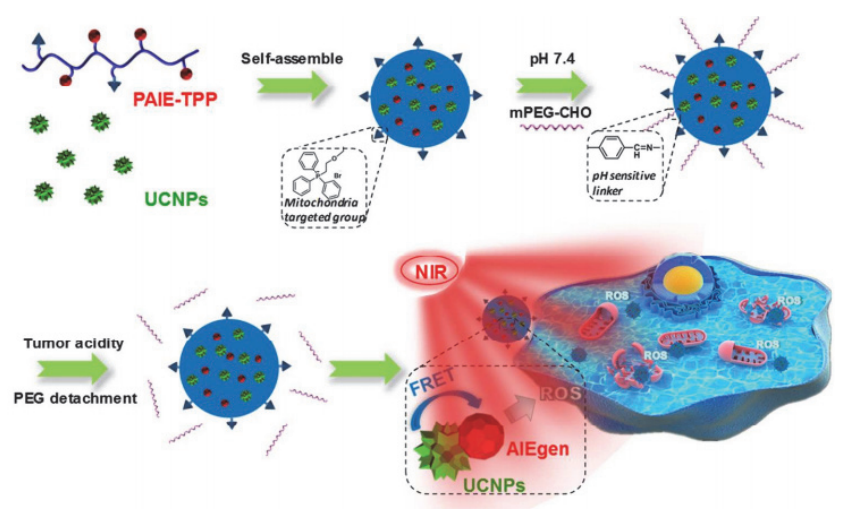

图 $5 \mathrm{pH}$ 刺激响应的UCNPs@PAIE-TPP-PEG 光动力诊疗探针的构建 示意图 ${ }^{[38]}$

Figure 5 Diagram of the pH-responsive UCNPs@PAIE-TPP-PEG photodynamic nanotheranostic probe ${ }^{[38]}$
进一步, Ling 等 ${ }^{[39]}$ 利用具有电荷反转特性的聚合物 配体构建了新型的 $\mathrm{pH}$ 刺激响应型上转换光动力诊疗探 针. 如图 6 所示, 该课题组采用化学方法将光敏剂分子 Ce6 共价修饰到聚合物单体链上，然后利用配体交换法 将聚合物修饰于 UCNPs 表面. 在正常血液 $\mathrm{pH}$ (约为 7.4) 中, 该上转换光动力诊疗探针表面带有负电荷, 光敏剂 在聚合物链中成聚集状态, 由于光敏剂的聚集诱导猝灭 现象，其光敏活性被抑制. 当该诊疗探针进入肿瘤部位， 在肿瘤微酸环境刺激下, 表面电荷迅速由负电变为正 电，通过内吞作用进入肿瘤细胞. 在内涵体/溶酶体等细 胞器中, 探针表面的正电性增强，由于电荷间排斥作用， 使聚合物解离, 光敏剂由聚集状态变为自由分散状态, 恢复其光敏活性. 该诊疗探针利用肿瘤微酸环境有效调 控光敏剂活性的 “关闭” 和 “开启” 状态，为构建精准 上转换光动力诊疗平台提供新思路.

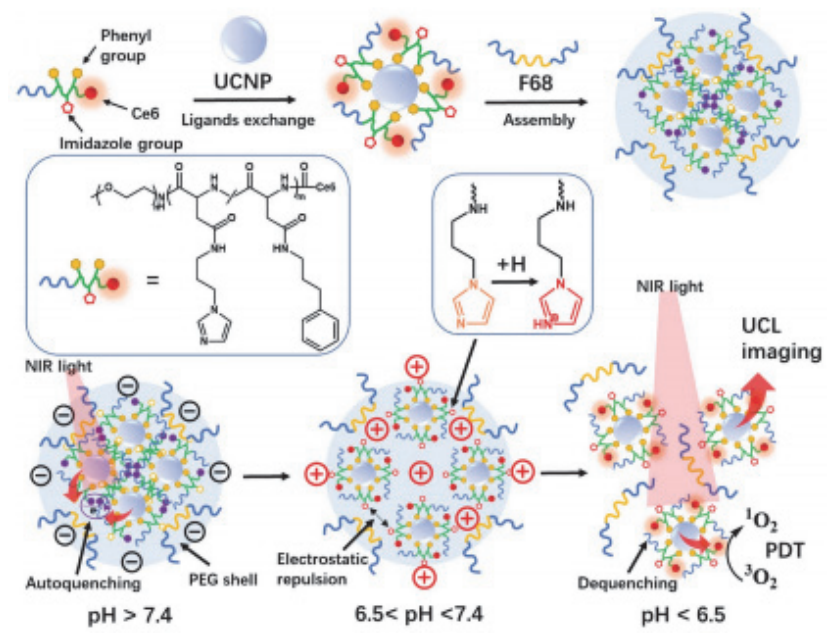

图 6 利用具有电荷反转特性的聚合物配体构建新型的 $\mathrm{pH}$ 刺激响应 型上转换光动力诊疗探针 ${ }^{[39]}$

Figure 6 Construction of novel pH-responsive photodynamic nanotheranostic probe based on the polymer with charge reversal properties ${ }^{[39]}$

抗调亡蛋白 Bcl-2 在调节细胞程序性死亡、参与抵 抗氧化刺激等方面发挥着重要作用 ${ }^{[23,40]}$. 因此, Bcl-2 的 抑制剂可以增强 PDT 效果. 然而, 在大多数情况下, 抑 制剂和光敏剂是单独注射的, 很难实现两者在肿瘤中的 同时最佳积累. 抗调亡蛋白 Bcl-2 在肿瘤细胞和正常细 胞中均表达. 因此，抑制 Bcl-2 在肿瘤细胞中的作用，同 时不影响其在正常细胞中的保护作用是需要注意的问 题. Kong 等 ${ }^{[41]}$ 利用酸性敏感的聚合物设计辅助干预策 略增强 PDT 体系. 如图 7 所示, 他们将光敏剂 ZnPc 通 过配体交换作用修饰于 UCNPs 表面，进而将酸性敏感 聚合物 poly(ethylene glycol)-poly( $L$-histidine) diblock copolymer (PEG- $b$-PHis)均匀修饰于 UCNPs 表面，并物 理负载 $\mathrm{ABT} 737$ 分子, 构建上转换光动力诊疗探针 ABT737@ZnPC-UCNPs. ABT737 分子是 Bcl-2 蛋白的抑 制剂，能与其疏水沟结合，防止 Bcl-2 蛋白的二聚化，进 一步诱导相关促调亡蛋白如 Bax 和 Bak 的释放 ${ }^{[42]}$. 该探 
针进入细胞后, 在溶酶体的酸性环境中, 外层功能聚合 物 PEG- $b$-PHis 的溶解性降低, 释放 ABT737 分子, 进 而诱导相关促调亡蛋白的释放和累积. 同时, 在 NIR 激 发下, UCNPs 发射的苂光有效激发光敏剂 ZnPc, 产生 ROSs, 发挥 PDT 效果.

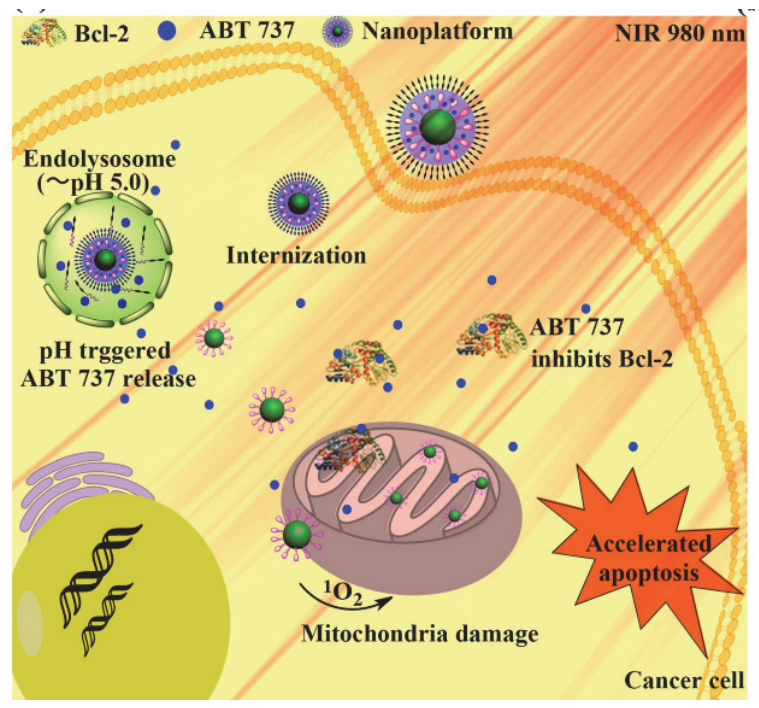

图 7 构建的 ABT737@ZnPC-UCNPs 纳米探针示意图 ${ }^{[41]}$

Figure 7 Diagram of the developed ABT737@ZnPC-UCNPs nanoprobe $^{[41]}$

$\mathrm{He}$ 等 ${ }^{[43]}$ 利用酸性可降解的磷酸钙壳包裹的 UCNPs 构建了新型的 $\mathrm{pH}$ 刺激响应型上转换协同诊疗体系. 如 图 8 所示, 该课题组利用高温热解法合成磁性 UCNPs, 进一步包覆 $\mathrm{mSiO}_{2}$, 并负载光敏剂 $\mathrm{Ce} 6$, 得到 $\mathrm{UCNPs} @ \mathrm{mSiO}_{2} / \mathrm{Ce} 6$, 然后利用模板方法在介孔二氧化 硅表面直接生长介孔磷酸钙壳后, 物理负载抗癌药物阿 需素 (doxorubicin, DOX), 得到上转换诊疗探针 UCNPs-Ce6@SiO $@ @$ calcium phosphate-DOX. 实验结果 表明, 该诊疗探针能够在肿瘤的微酸环境中迅速降解,

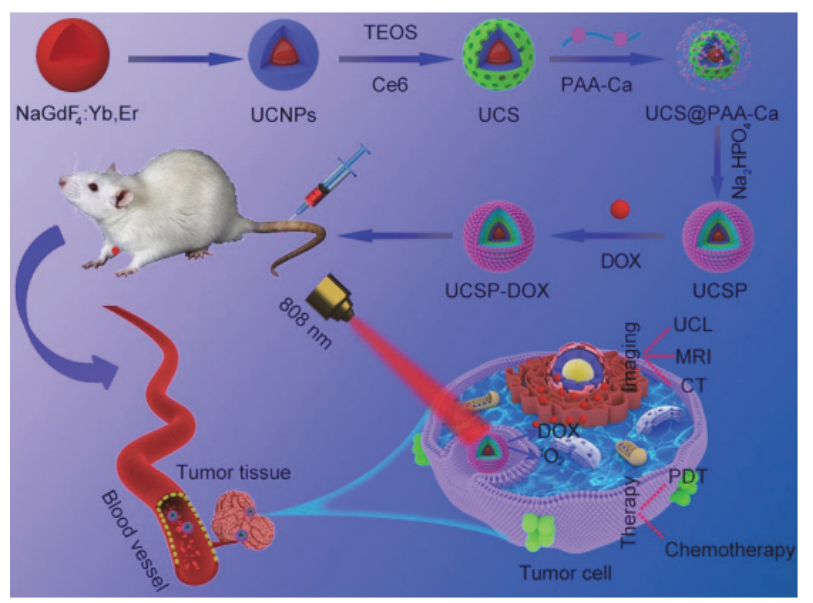

图 $8 \mathrm{pH}$ 刺激响应型药物载体 UCNPs-Ce6@SiO $@$ @calcium phosphate-DOX 用于肿瘤的化学药物治疗和上转换光动力治疗 ${ }^{[43]}$

Figure 8 pH-responsive UCNPs-Ce6@SiO $\mathrm{Si}_{2} @$ calcium phosphate-DOX drug carrier for the chemotherapy and upconversion photodynamic therapy $^{[43]}$
释放负载的 $\mathrm{DOX}$. 当溶液 $\mathrm{pH}$ 降低至 6.5 时, $\mathrm{DOX}$ 累计 释放率为 $59.7 \%$, 当 $\mathrm{pH}$ 进一步降低至 5.0, DOX 的累计 释放率高达 $92 \%$. 同时，该诊疗探针在 $808 \mathrm{~nm}$ 的激光照 射下，激发光敏剂 Ce6，产生 ROSs，实现 PDT.

基于叶酸构建靶向性上转换光动力诊疗探针是常 用的方法. 然而, 肿瘤周围的正常组织细胞表面也表达 一定量的叶酸受体. 因此, 基于叶酸构建的靶向性诊疗 探针对正常组织具有潜在的毒副作用. 为了解决这一问 题，Tang 等 ${ }^{[44]}$ 通过在 UCNPs 表面修饰不同长度的两种 DNA 序列, 构建 $\mathrm{pH}$ 刺激响应的 $\mathrm{DNA}$ /上转换纳米复合 物(UCNPs@PAA-DNA), 提出构建精确肿瘤靶向和刺激 响应的 PDT 预保护策略. 如图 9 所示, 较短 DNA 序列 上的叶酸分子 FA, 在正常组织中受到较长 DNA 序列的 保护, 避免了纳米颗粒在正常组织的聚集. 当到达肿瘤 区域, UCNPs@PAA-DNA 纳米复合物中较长的 DNA 在 酸性肿瘤微环境中折叠, 暴露短 DNA 序列上的 FA 分子 以实现癌细胞的靶向. 折叠的长链 DNA 上光敏剂 $\mathrm{Ce} 6$ 接近 UCNPs 表面, 改善了 PDT 的治疗效果. 这种预防 保护策略为精确定位和高效癌症治疗提供了新的思路.

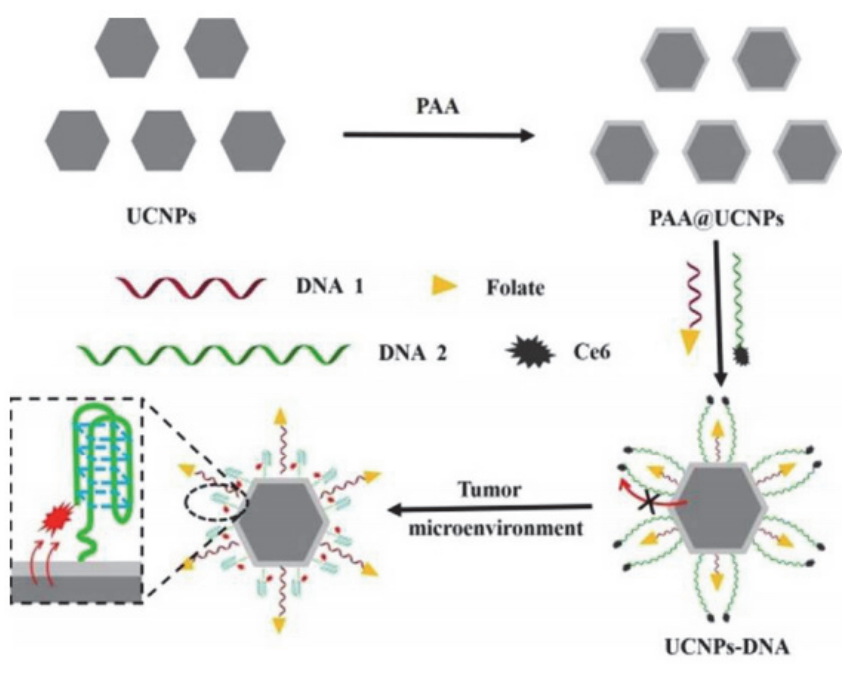

图 9 肿瘤微酸环境刺激响应的上转换光动力诊疗探针的构建和预保 护策略的构建 ${ }^{[4]}$

Figure 9 Construction of pH-responsive upconversion photodynamic probes and the pre-protective strategy ${ }^{[44]}$

\section{2 特异性酶刺激响应型上转换光动力诊疗探针的构 建}

酶是一种重要的生物催化剂, 参与细胞中几乎所有 的生物过程. 由于其高特异性和良好的选择性, 酶成为 设计和构建响应型治疗诊断的有效触发因素.

组织蛋白酶 B(Cathepsin B, CaB) 作为溶酶体蛋白酶 家族的一员, 在多种癌症如乳腺癌和胰腺癌中过表达, 被认为是一种潜在的生物标志物 ${ }^{[45]}$. 此外, 组织蛋白酶 B 能够选择性切割特定序列肽即 Gly-Phe-Leu-Gly 或 Arg-Arg-Lys, 因此组织蛋白酶被广泛用作肿瘤部位特 异性成像和刺激响应的触发因素. 
$\mathrm{Liu}$ 等 ${ }^{[46]}$ 构建了一种细胞内 $\mathrm{CaB}$ 刺激响应型上转换 光动力诊疗探针, 并且利用苂光共振能量转移策略实时 监测治疗效果. 首先, 利用热解法合成核壳式 UCNPs, 然后在其表面修饰阿仓膦酸(Alendronic acid, ADA), 并 负载近红外染料 $800 \mathrm{CW}$, 增强 UCNPs 的发光强度. 进 一步 UCNPs 材料表面修饰光敏剂 RB, 染料 Cy3 和猝灭 基团 QSY7 修饰的多肽 GRRGLGC (简写为 Pep-QSY7). 在 $808 \mathrm{~nm}$ 激光照射下, 发生两个能量转移过程(如图 10 所示). 能量转移 1: UCNPs 发射的 $540 \mathrm{~nm}$ 苂光激发 Cy3, 处于激发态的 Cy3 能量被猝灭基团 QSY7 猝灭; 能量转 移 2: UCNPs 发射的 $540 \mathrm{~nm}$ 荧光激发光敏剂 RB, 处于 激发态的 RB 分子, 其能量进一步被猝灭基团 QSY7 猝 灭. 此时, RB 分子的光敏活性被抑制, PDT 处于 “off” 状态. 癌细胞内过表达的 $\mathrm{CaB}$ 特异性识别并切断多肽 链, 使猝灭基团 QSY7 远离 UCNPs 表面, 此时能量转移 过程发生改变, 能量转移过程 1 变为 UCNPs 发射的 540 $\mathrm{nm}$ 苂光激发 $\mathrm{Cy} 3$, 发射 $583 \mathrm{~nm}$ 的荧光; 能量转移过程 2 变为 UCNPs 发射的 $540 \mathrm{~nm}$ 荧光激发光敏剂 RB, 此时 处于激发态的 RB 分子能量与组织周围的氧气等发生反 应生成 ROSs, PDT 处于 “on” 状态. 该工作通过肿瘤细 胞内过表达的酶调控光敏剂的激活过程, 实现可控 PDT. 同时, 利用比率苂光 $\mathrm{FI}_{583} / \mathrm{FI}_{540}$ 可以追踪和预测光 动力治疗效果.
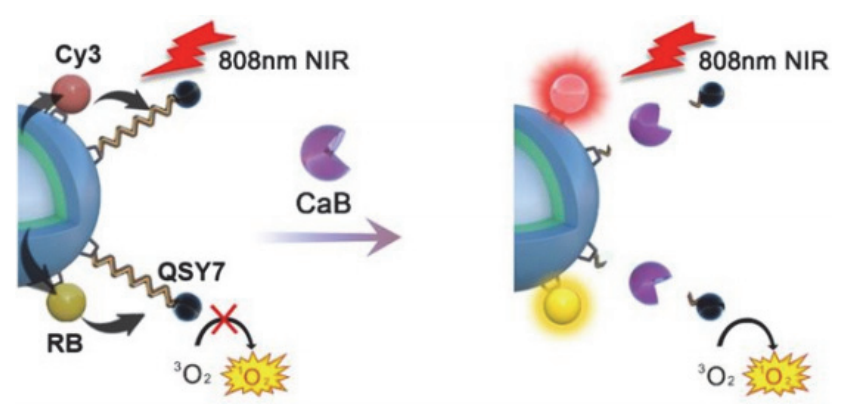

图 10 利用 $\mathrm{CaB}$ 酶特异性识别的多肽链和 UCNPs 构建两元能量转移 过程 ${ }^{[46]}$

Figure 10 Dual energy transfer process between peptide recognized specially by $\mathrm{CaB}$ enzyme and $\mathrm{UCNPs}^{[46]}$

2016 年, Xing 课题组 ${ }^{[47]}$ 构建了 $\mathrm{CaB}$ 刺激的 UCNPs 诊疗体系实现了高效的肿瘤靶向性和有效的治疗 (如图 11 所示). 他们合成了 $\mathrm{Nd}^{3+}$ 掺杂的 UCNPs, 利用 Stöber 法在其表面包覆一层致密硅, 用于负载光敏剂 Ce6, 然 后修饰上短肽 $\mathrm{C}$ (stbu)- $\mathrm{K}-\mathrm{F}$ 和 2-氰基苯并噻唑(CBT). 肿 瘤细胞中过表达的 $\mathrm{CaB}$ 特异性识别并切断 UCNPs 表面 的短肽 $\mathrm{C}(\mathrm{stbu})-\mathrm{K}-\mathrm{F}$, 暴露出的半胱氨酸与相邻 UCNPs 表面的 2-氰基苯并噻唑(2-cyanobenzothiazole, CBT)共 价交联, 引起 UCNPs 在肿瘤部位的高效积累. 在 NIR 激发下，聚集的 UCNPs 激发光敏剂 Ce6, 产生增强的 PDT 疗效. 实验结果表明, 该策略可以实现肿瘤部位的 特异性苂光成像和增强的 PDT.
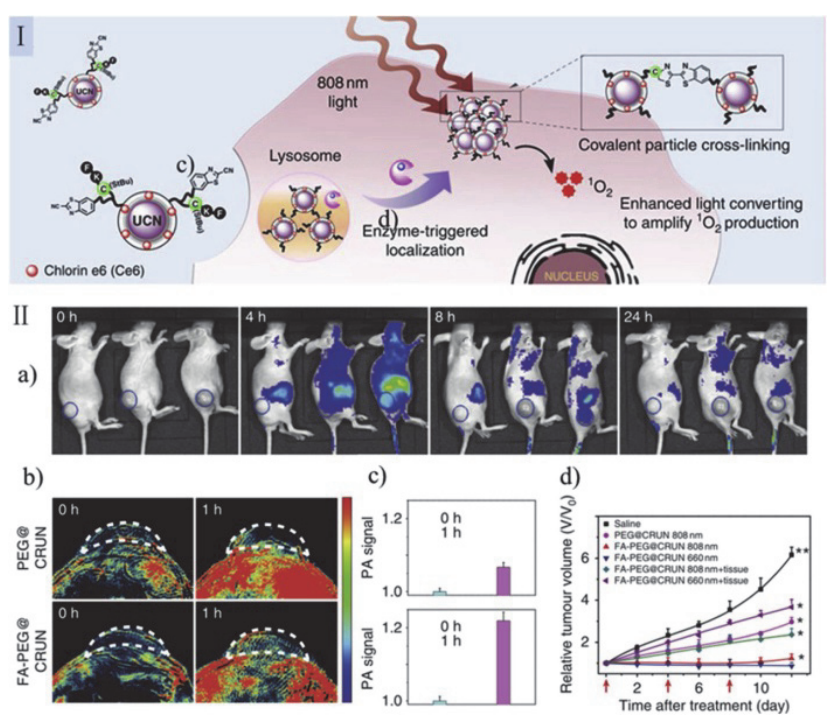

图 11 (I) 用于肿瘤部位短肽修饰的 UCNPs 在 $\mathrm{CaB}$ 刺激下共价交联 的策略示意图; (II) (a) 注射探针后在不同时间间隔内小鼠中肿瘤部位 (蓝色圆圈)的荧光成像; $(b, c)$ 静脉内注射探针后不同时间间隔内肿 瘤区域的 PA 成像信号; (d) 在不同探针处理下肿瘤体积随时间的变化 曲线 $[47]$

Figure 11 (I) Illustration of the Cathepsin $\mathrm{B}(\mathrm{CaB})$-sensitive strategy for covalent cross-linking of peptide modified UCNPs in tumour areas; (II) (a) Fluorescence imaging of tumors (blue circle) in living mice at different time interval after injection; (b, c) PA imaging signals in the tumor region at different time intervals after intravenous injection; (d) Tumor volumes change as a function of time in different treated groups ${ }^{[47]}$

\section{3 过氧化氢等氧化环境增强型上转换光动力诊疗体} 系

生物系统中的 ROSs 如单线态氧 ${ }^{1} \mathrm{O}_{2}$ 、过氧化氢 $\mathrm{H}_{2} \mathrm{O}_{2}$ 、羟基自由基・ $\mathrm{OH}$ 、超氧化物 $\mathrm{O}_{2}{ }^{-{ }^{-}}$、次氯酸 $\mathrm{HOCl}$ 和过氧亚硝酸盐 $\mathrm{ONOO}^{-}$, 对细胞信号传导、稳态、增 殖和衰老等多种生物事件有重要影响 ${ }^{[48]}$. 由于癌细胞 中 ROSs 的浓度高于正常细胞, 因此 ROSs 可以用于构 建刺激响应型诊疗体系.

一些催化剂如过氧化氢酶(catalase, CAT) ${ }^{[49,50]}$ 、二氧 化锰 $\left(\mathrm{MnO}_{2}\right)$ 纳米片 ${ }^{[23,51]} 、 \mathrm{MnFe}_{2} \mathrm{O}_{4}$ 纳米材料 ${ }^{[52]} 、 \mathrm{ZnFe}_{2} \mathrm{O}_{4}$ 纳米材料 ${ }^{[53]}$ 和氧化铈 $\left(\mathrm{CeO}_{x}\right)$ 纳米材料 ${ }^{[54]}$ 等可以催化和 分解过氧化氢 $\left(\mathrm{H}_{2} \mathrm{O}_{2}\right)$ 产生氧气, 有利于改善肿瘤的乏氧 条件, 提高 PDT 效果. 因此, 研究工作者主要利用这些 催化剂与肿瘤微环境中高浓度的过氧化氢发生反应，构 建增强型上转换光动力治疗体系.

Lin 等 ${ }^{[50]}$ 利用两步点击反应合成 UCNPs-树状大分 子复合材料. 该材料表现出优异的溶解性、稳定性、良 好的生物相容性，具有亲水性和疏水性空穴，有利于同 时负载疏水性光敏剂 Ce6 和亲水性过氧化氢酶. 如图 12 所示，在线粒体靶向基团的驱动下，该复合材料富集于 线粒体. 在 NIR 激发下, UCNPs 的苂光有效激活光敏剂 Ce6 产生 ROSs. 同时，负载的过氧化氢酶能够有效催化 过表达的过氧化氢生成氧气, 增强上转换光动力治疗效 果. 


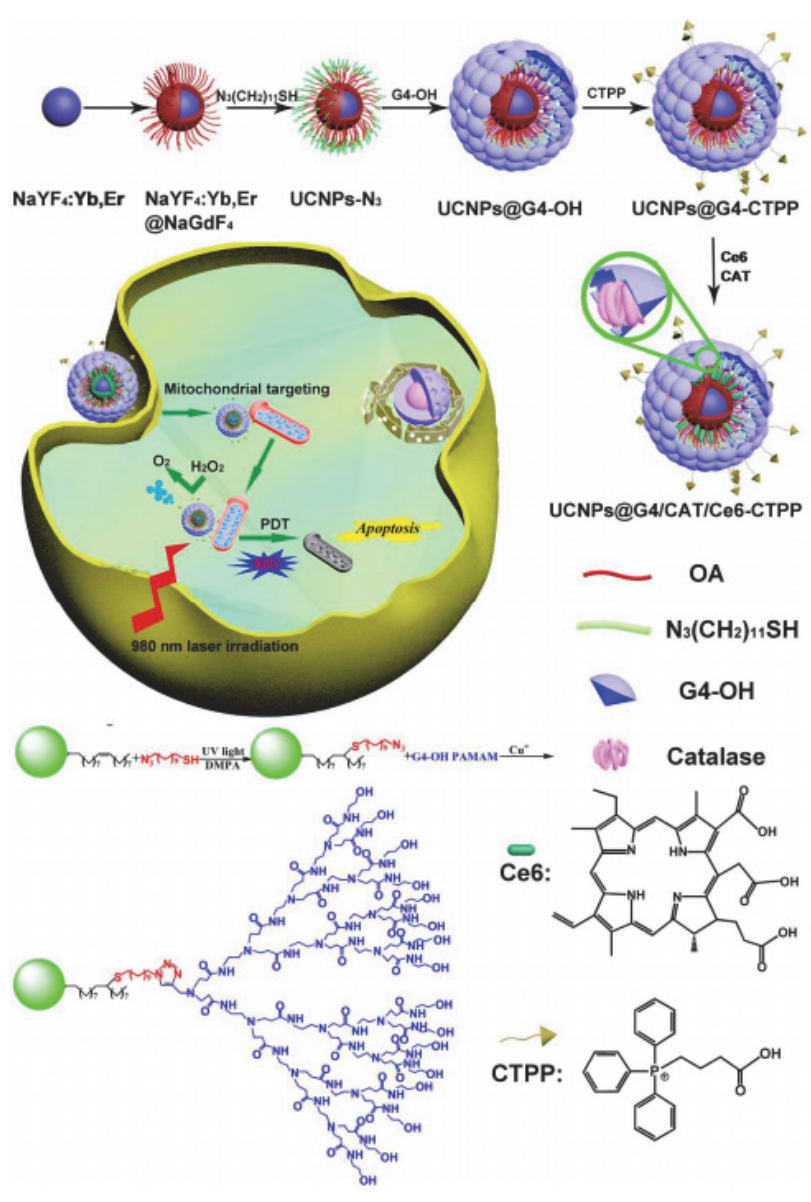

图 12 两步点击反应合成 UCNPs-树状大分子复合物, 并进一步负载 光敏剂 $\mathrm{Ce} 6$ 和过氧化氢酶, 构建过氧化氢增强的 $\mathrm{PDT}^{[50]}$

Figure 12 UCNPs-dendrimer complex synthesized by two-step click reaction and further loaded with photosensitizer $\mathrm{Ce} 6$ and catalase to construct hydrogen peroxide enhanced $\mathrm{PDT}^{[50]}$

研究结果表明, $\mathrm{MnO}_{2}$ 纳米材料能够发生分解, 生成 氧气, 有效改善肿瘤的乏氧环境, 提高氧气依赖型 PDT 的治疗效果(如图 13 所示 $)^{[55]}$. 同时, 释放的 $\mathrm{Mn}^{2+}$ 具有 良好的生物相容性, 增加的顺磁性和驰豫速率 $\left(r_{1}, 1 / \mathrm{T}_{1}\right)$, 能够实现 $\mathrm{T}_{1}$ 型 $\mathrm{MRI}$.

$$
\begin{gathered}
\mathrm{MnO}_{2}+\mathrm{H}^{+} \longrightarrow \mathrm{Mn}^{2+}+\mathrm{H}_{2} \mathrm{O}+1 / 2 \mathrm{O}_{2} \uparrow \\
\mathrm{MnO}_{2}+\mathrm{H}_{2} \mathrm{O}_{2}+\mathrm{H}^{+} \longrightarrow \mathrm{Mn}^{2+}+2 \mathrm{H}_{2} \mathrm{O}+2 \mathrm{O}_{2} \uparrow \\
\mathrm{MnO}_{2}+2 \mathrm{GSH}+2 \mathrm{H}^{+} \longrightarrow \mathrm{Mn}^{2+}+\mathrm{GSSH}+2 \mathrm{H}_{2} \mathrm{O}_{2} \uparrow
\end{gathered}
$$

图 $13 \mathrm{MnO}_{2}$ 纳米材料在酸性条件下与 $\mathrm{H}_{2} \mathrm{O}_{2}$ 和 $\mathrm{GSH}$ 的反应 ${ }^{[5]}$

Figure 13 Reaction progress of $\mathrm{MnO}_{2}$ nanomaterials with $\mathrm{H}_{2} \mathrm{O}_{2}$ 和 $\mathrm{GSH}$ in acid condition ${ }^{[55]}$

目前, 如图 14 所示, 研究工作者成功合成了基于 $\mathrm{MnO}_{2}$ 纳米片修饰的 $\mathrm{UCNPs}^{[56-61]}$, 蜂巢状 $\mathrm{MnO}_{2}$ 纳米材

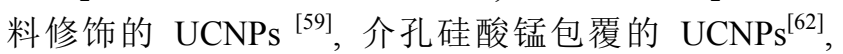
$\mathrm{Mn}^{2+}$ 掺杂 UCNPs@ 介孔二氧化硅纳米材料 ${ }^{[63]}$, $\mathrm{UCNPs} @ \mathrm{mSiO}_{2} @ \mathrm{mMnO}_{2}$ 纳米材料 ${ }^{[55]}$ 和蛋黄式介孔 $\mathrm{mMnO}_{2}$ 包裹的 UCNPs $\left(\mathrm{UCNPs} @ \mathrm{mMnO}_{2}\right)^{[64]}$.

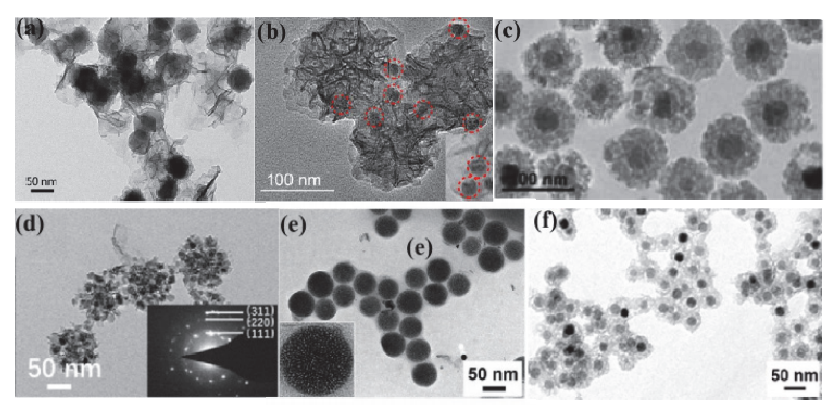

图 14 (a) $\mathrm{MnO}_{2}$ 纳米片修饰的 UCNPs ${ }^{[57]}$; (b) 蜂巢状 $\mathrm{MnO}_{2}$ 纳米材料 修饰的 UCNPs ${ }^{[59]}$; (c) 介孔硅酸锰包覆的 $\mathrm{UCNPs}^{[62]}$; (d) $\mathrm{Mn}^{2+}$ 掺杂

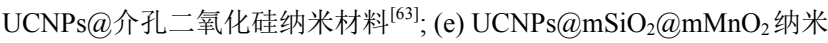
材料 ${ }^{[5]}$; (f) 蛋黄式介孔 $\mathrm{mMnO}_{2}$ 包裹的 UCNPs (UCNPs@ $\left.@ \mathrm{mMnO}_{2}\right)^{[64]}$ 图 14 (a) $\mathrm{MnO}_{2}$ nanosheet modified UCNPs ${ }^{[57]}$; (b) Honeycomb structured $\mathrm{MnO}_{2}$ nanomaterials modified UCNPs ${ }^{[59]}$; (c) Mesoporous manganese silicate coated UCNPs ${ }^{[62]}$; (d) $\mathrm{Mn}^{2+}$ doped UCNPs@mesoporous silica nanomaterials ${ }^{[63]}$; (e) UCNPs@ $\mathrm{mSiO}_{2} @ \mathrm{mMnO}_{2}$ nanomaterials ${ }^{[55]}$; (f) yolk structured UCNPs@mMnO ${ }^{\left[{ }^{[64]}\right.}$

2015 年, Shi 等 ${ }^{[61]}$ 首次将硅层包裹的 UCNPs 负载于 $\mathrm{MnO}_{2}$ 纳米片上. 同时, 通过硅烷化反应将光敏剂 SPCD 负载于硅层中. 实验结果表明, $\mathrm{MnO}_{2}$ 纳米片在 300 $600 \mathrm{~nm}$ 区间具有较强的吸收强度, 能够有效地猝灭 UCNPs 苂光, 抑制光敏剂的光敏活性. 而在酸性条件 下, $\mathrm{MnO}_{2}$ 纳米片能够与过氧化氢快速发生反应, 生成氧 气, 并降解成为游离的 $\mathrm{Mn}^{2+}$, 使硅层包裹的 UCNPs 释 放出来, 恢复其苂光, 进而通过 LRET 过程激发光敏剂, 产生 ROSs. 同时, $\mathrm{MnO}_{2}$ 纳米片良好的产氧能力能够有 效地改善肿瘤的乏氧条件, 提高光敏剂产生 ROSs 的能 力, 增强 PDT 效果.

Xing 等 ${ }^{[58]}$ 合成了 PAA 修饰的 UCNPs, 然后负载 $\mathrm{MnO}_{2}$ 纳米片，进一步修饰氨基化聚合物，PEI，以利于 通过化学作用负载光敏剂 Ce6, 最后修饰透明质酸 (Hyaluronic acid, HA)生物聚合物(如图 15 所示). 实验结 果表明, $\mathrm{MnO}_{2}$ 纳米片能够有效地提高氧气依赖型 PDT 的治疗效果. 此外, HA 可以有效地重调 M2 表型吞噬细 胞向抗肿瘤 M1 表型吞噬细胞的极化，以抑制 PDT 治疗

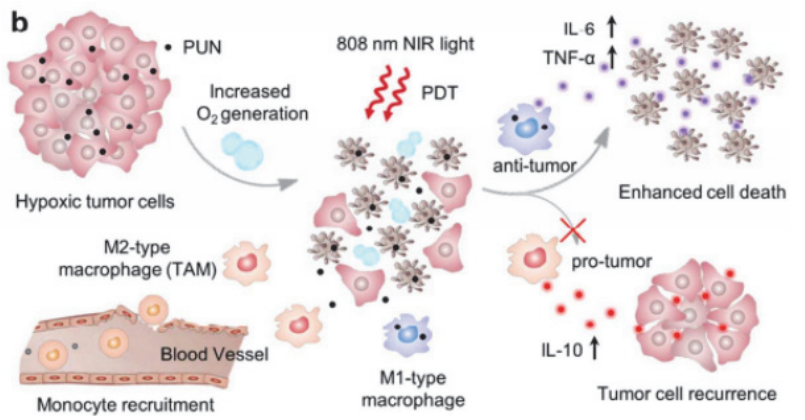

图 15 NIR 介导的 PDT 治疗后, 通过改变肿瘤的乏氧条件和重编辑 肿瘤相关吞噬细胞从 M2 表型到 M1 表型来抑制肿瘤细胞的复发 ${ }^{[58]}$

Figure 15 Scheme of improved therapy by attenuating hypoxia status and reprogramming tumor-associated macrophages (TAMs) from M2 to M1 phenotype to inhibit the recurrence of tumor cells toward immunotherapy during the post-PDT period ${ }^{[58]}$ 
后肿瘤的复发. 该工作证明结合免疫治疗可有效抑制 PDT 治疗后的肿瘤复发.

然而, UCNPs 直接负载在 $\mathrm{MnO}_{2}$ 纳米片表面时, $\mathrm{MnO}_{2}$ 纳米片会影响 UCNPs 的分散性. 如图 16 所示, Liu 课题组 ${ }^{[63]}$ 利用毛细作用和热解反应在介孔二氧化硅孔 中生成 $\mathrm{CaF}_{2}: \mathrm{Yb}, \mathrm{Er}$ 纳米晶, 进一步将 $\mathrm{Mn}^{2+}$ 离子负载到 $\mathrm{CaF}_{2}: \mathrm{Yb}$, Er 纳米晶的晶格中, 形成杂化纳米材料, 并负 载光敏剂 Ce6. 实验结果表明, $\mathrm{Mn}^{2+}$ 离子的掺杂将有效 地增加 $\mathrm{Er}^{3+}$ 的交换能量转移过程, 增加在 NIR 激发下 UCNPs 红色荧光的发射强度, 有利于光敏剂 Ce6 的激 发. 小动物实验结果表明, 制备的探针能够有效抑制肿 瘤生长, 并使肿瘤体积减小.

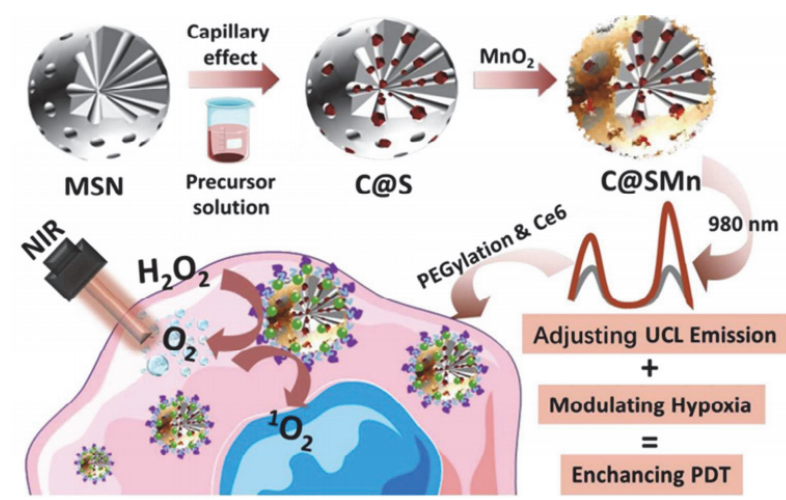

图 $16 \mathrm{C} @ \mathrm{SMn}-\mathrm{Ce} 6$ 的制备和增强 PDT 治疗过程示意图 ${ }^{[63]}$

Figure 16 Diagram of the preparation of C@SMn-Ce6 and the process of enhanced $\mathrm{PDT}^{[63]}$

除了负载有机光敏剂, $\mathrm{MnO}_{2}$ 纳米材料也可以作为 无机光敏剂或结合其它无机光敏剂构建氧化环境增强 型上转换光动力诊疗体系. Tian 等 ${ }^{[65]}$ 利用二氧化锰 $\mathrm{MnO}_{2}$ 作为半导体合成了一种核壳型上转换光动力诊疗 探针. 如图 17 所示, 该课题组通过在 UCNPs 表面原位 生长一层 $\mathrm{MnO}_{2}$ 壳, 构建核壳型上转换光动力诊疗探针. 实验结果表明, 在 NIR 激发下, UCNPs 发射的紫外菼光 能够有效激发 $\mathrm{MnO}_{2}$ 壳, 产生电子-空穴对, 然后与氧气 和水等发生反应，生成过氧化氢和单线态氧等 ROSs.

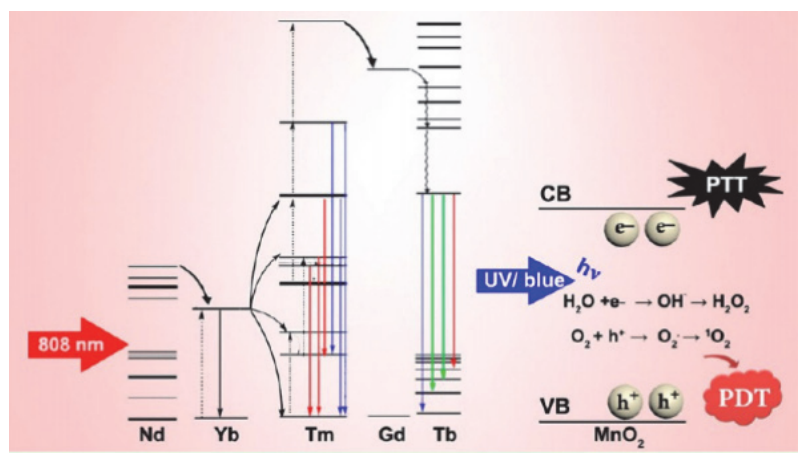

图 $17 \mathrm{MnO}_{2}$ 壳包裹的 UCNPs 在 $808 \mathrm{~nm}$ 激发下的能量转移和产生 ROSs 过程 ${ }^{[65]}$

Figure 17 Energy transfer and ROSs produced process of $\mathrm{MnO}_{2}$ shell coated UCNPs under the excitation of $808 \mathrm{~nm}$ laser ${ }^{[65]}$
同时，在 $808 \mathrm{~nm}$ 激光激发下温度升高 $12.2{ }^{\circ} \mathrm{C}$, 实现 PDT 和光热治疗协同效果.

Zhang 等 ${ }^{[66]}$ 构建了多功能 $\mathrm{UCNPs@TiO} 2 @ \mathrm{MnO}_{2}$ 纳 米复合材料(UTMs)用于自补充氧气和 ROSs 循环扩增 的 PDT(如图 18 所示). $\mathrm{MnO}_{2}$ 纳米片在酸性环境中催化 细胞内过氧化氢生成氧气. 通过 $\mathrm{MnO}_{2}$ 纳米片的分解和 NIR 辐射, UCNPs 可以有效地将 NIR 转换为紫外光以激 活 $\mathrm{TiO}_{2}$ 产生有毒的 ROSs, 用于深层肿瘤治疗. 此外, 细胞内超氧化物歧化酶能够催化超氧化物再生过氧化 氢和氧气，进一步与 $\mathrm{MnO}_{2}$ 反应，循环放大 $\mathrm{ROSs}$ 的产生 量, 获得显著增强的 PDT 结果.

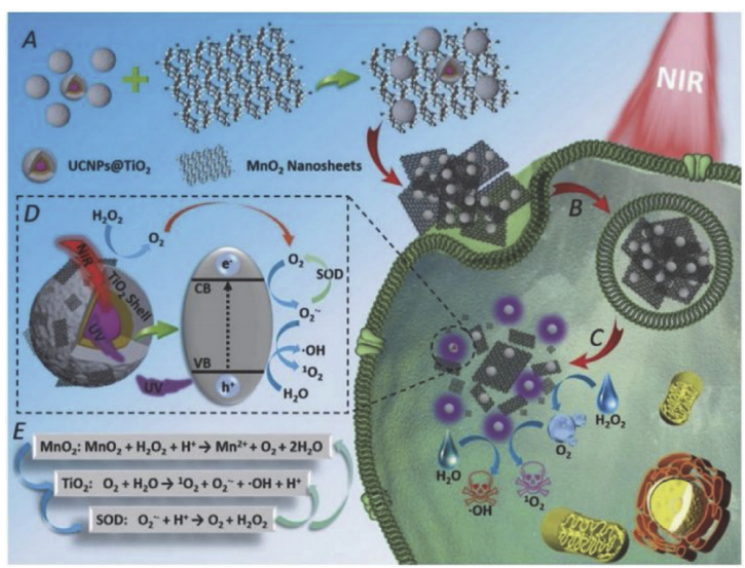

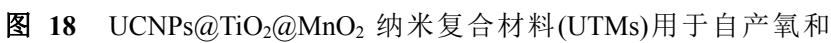
ROSs 循环增强 PDT 的示意图 ${ }^{[66]}$

Figure 18 Schematic illustration of UCNPs@TiO $@ \mathrm{MnO}_{2}$ nanocomposites (UTMs) for $\mathrm{O}_{2}$ self-supplemented and ROSs circulating amplified $\mathrm{PDT}^{[66]}$

Yang 等 ${ }^{[54]}$ 通过刻蚀和煅烧法在 UCNPs 表面涂覆了 一层介孔氧化铈纳米壳 $\left(\mathrm{mCeO}_{x}\right)$, 得到 $\mathrm{UCNPs} @ \mathrm{mCeO}_{x}$. 进一步在其表面修饰磷酸丝氨酸和 PEG 后负载抗癌药 物 DOX. 如图 19 所示, 在 NIR 激发下, UCNPs 发射的 紫外光能够有效激发 $\mathrm{mCeO}_{x}$, 产生 $\mathrm{ROSs}$. 同时, $\mathrm{mCeO}_{x}$ 具有良好的类过氧化氢酶活性，与过氧化氢发生氧化还 原反应，生成氧气，有效提高 PDT 和化疗治疗的疗效. 实验结果表明，该探针能够诱导 $88.7 \%$ 的细胞调亡，并 能够有效地抑制肿瘤生长.

$\mathrm{Hu}$ 等 ${ }^{[67]}$ 利用 $\mathrm{g}-\mathrm{C}_{3} \mathrm{~N}_{4}$ 和 $\mathrm{CeO}_{x}$ 设计了一种过氧化氢 敏感型上转换光动力治疗用于治疗深层肿瘤组织. 如图 20 所示, 该课题组首先制备核壳结构的 UCNPs, $\mathrm{NaGdF}_{4}: \mathrm{Yb}, \mathrm{Tm} @ \mathrm{NaGdF}_{4}: \mathrm{Yb}, \mathrm{Nd}$. 然后，将合成的 g- $\mathrm{C}_{3} \mathrm{~N}_{4} / \mathrm{CeO}_{x}(x=1 \sim 2)$ 沉积在 UCNPs 表面. 进一步将二 甲双胍(metformin, Met)负载到纳米材料表面, 得到最终 纳米团簇材料, UCNPs@ $\left(\mathrm{g}-\mathrm{C}_{3} \mathrm{~N}_{4} / \mathrm{CeO}_{x}\right.$ )-Met (简写为 UCGM NPs). 制备的纳米团簇材料通过增强渗透性和 滞留效应(enhanced permeability and retention, EPR)聚集 于肿瘤组织部位. $\mathrm{CeO}_{x}$ 层与过氧化氢发生反应生成氧 气. 氧气的释放使得部分 $\mathrm{g}-\mathrm{C}_{3} \mathrm{~N}_{4}$ 从 UCGM 纳米颗粒表 面游离下来, 进一步深入肿瘤内部. 同时, 释放下来的 
二甲双胍化合物能够有效抑制肿瘤细胞的呼吸作用. 因 此, 肿瘤部位的含氧量增加, 同时肿瘤细胞的耗氧量降 低. 在 $808 \mathrm{~nm}$ 激光照射下, UCNPs 发射的紫外和可见光 将有效激发 $\mathrm{g}-\mathrm{C}_{3} \mathrm{~N}_{4}$ 纳米颗粒产生超氧阴离子和羟基自 由基. 该纳米材料还能够实现三模式成像, 包括上转换 发光成像, MRI 和 PET.

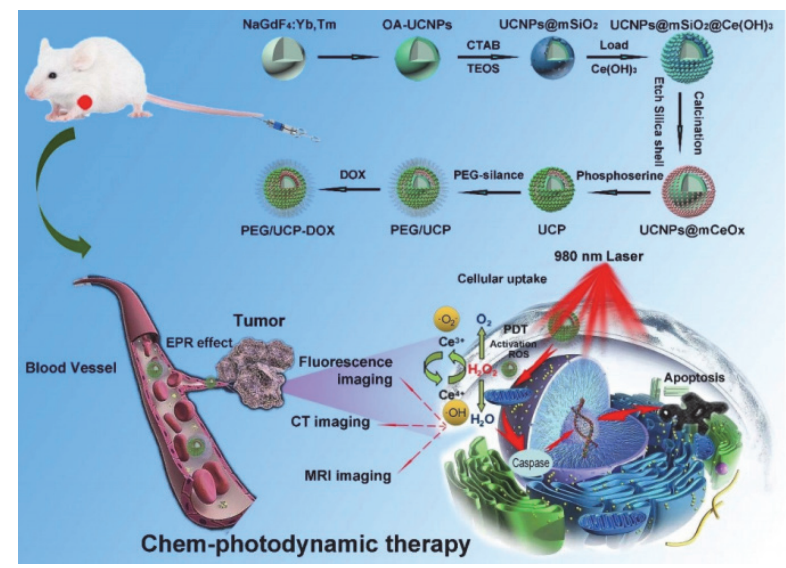

图 19 介孔氧化铈纳米壳修饰的 UCNPs 纳米体系的构建以及在血管 中运输、基于 EPR 效应肿瘤部位富集以及光动力治疗和化学治疗的 示意图 ${ }^{[54]}$

Figure 19 Schematic illustration for the formation and transport of UCNPs@ $\mathrm{mCeO}_{x}$ nanomaterials in blood vessel, EPR-mediated tumor accumulation, proposed PDT and chemotherapy ${ }^{[54]}$

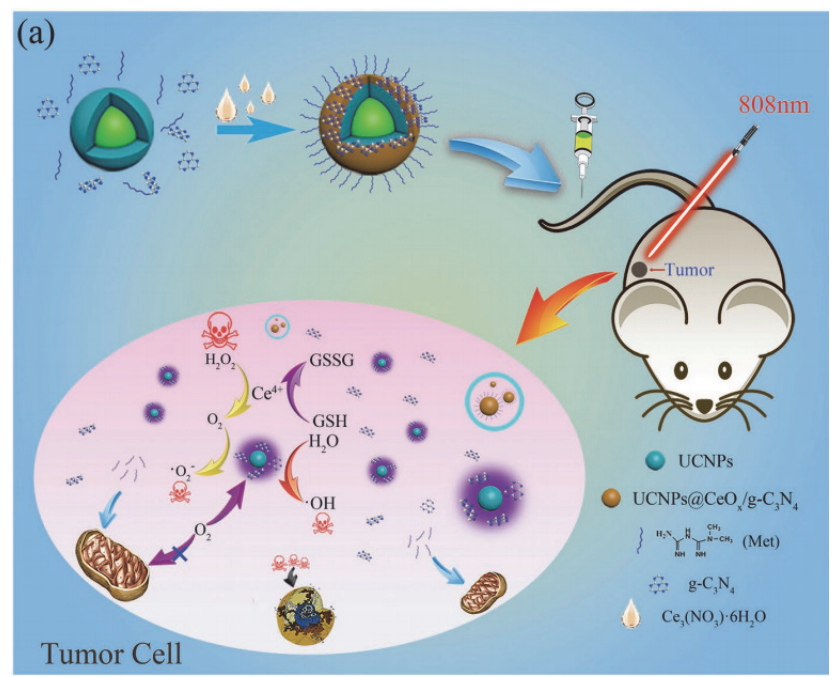

图 20 过氧化氢敏感上转换纳米团簇用于深层肿瘤组织的上转换光 动力治疗 ${ }^{[67]}$

Figure 20 Upconversion photodynamic therapy based on $\mathrm{H}_{2} \mathrm{O}_{2}$ sensitive upconversion nanoclusters for deep-seated tumor section ${ }^{[67]}$

近期, 化学动力治疗 (Chemical dynamic therapy, CDT)作为新型癌症治疗策略引起了研究者的极大兴趣. CDT 利用芬顿反应将细胞内过氧化氢转化为具有细胞 毒性的羟基自由基.

Lin 等 ${ }^{[52]}$ 合成了 $\mathrm{MnFe}_{2} \mathrm{O}_{4}$ 纳米颗粒修饰的 UCNPs 纳米材料 $(\mathrm{UCMnFe})$. 实验结果表明, $\mathrm{UCMnFe}$ 纳米材料 具有较大的介孔结构, 能够有效地负载光敏剂, 光敏剂
的负载效率为 $11.33 \mathrm{wt} \%$. 约 $10 \mathrm{~nm}$ 的 $\mathrm{MnFe}_{2} \mathrm{O}_{4}$ 纳米颗 粒能够作为芬顿反应催化剂, 在肿瘤部位的酸性和过表 达的过氧化氢刺激下，发生多步氧化还原反应，生成 $\mathrm{Mn}^{2+} 、 \mathrm{Fe}^{3+}$ 和氧气, 有效提高 PDT 效果.

铁离子参与的芬顿反应可以将细胞内过氧化氢转 化为具有细胞毒性的羟基自由基. 但是, 该反应在较低 $\mathrm{pH}(\mathrm{pH}=3 \sim 4)$ 下才具有较高的反应速度和反应效率. 因此, 铁离子参与的芬顿反应在肿瘤微酸环境中反应效 率受限. 紫外线照射可以诱导光芬顿反应，加快芬顿反 应速度，并提高其反应效率. UCNPs 可以在 NIR 光激发 下，充当 UV 源以辅助芬顿反应，改善 ROSs 的产生.

Shi 等 ${ }^{[68]}$ 报道了基于肿瘤特异性芬顿反应的上转换 光动力诊疗体系(UCSRF). 如图 21 所示, 在该体系中, UCNPs 核将 NIR 光转换为紫外-可见光激发光芬顿反 应, 介孔二氧化硅作为芬顿试剂 $\left(\mathrm{Fe}^{2+}\right)$ 的载体, $\mathrm{Ru}^{2+}$ 复合 物修饰到介孔二氧化硅表面用于靶向线粒体 DNA. 在 NIR 照射下，聚集于肿瘤细胞线粒体内的 UCSRF，与过 氧化氢发生光芬顿反应，产生羟基自由基，引起线粒体 DNA 损伤。

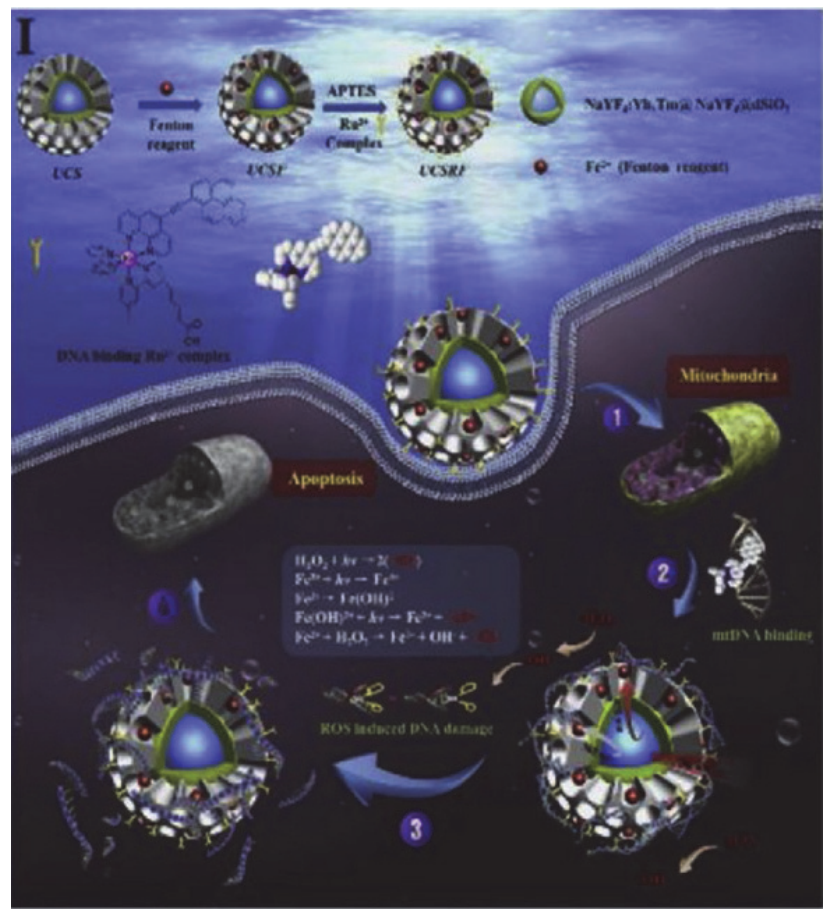

图 $21 \mathrm{UCSRF}$ 的合成和基于光芬顿反应的线粒体 DNA 靶向治疗的 示意图 ${ }^{[68]}$

Figure 21 Schematic illustration for the UCSRF synthesis and mitochondria DNA targeted therapy based on the photofenton reaction ${ }^{[68]}$

除了 $\mathrm{MnFe}_{2} \mathrm{O}_{4}, \mathrm{ZnFe}_{2} \mathrm{O}_{4}$ 具有较窄的带隙 $(1.9 \mathrm{eV})$, 良好的光化学稳定性、强磁性和高效的光催化能力. 如 图 22 所示, $\mathrm{ZnFe}_{2} \mathrm{O}_{4}$ 可以在紫外光下通过直接电子转移 生成 ROSs，其中包含的 $\mathrm{Fe}^{3+} / \mathrm{Fe}^{3+}$ 可以通过芬顿反应生 成羟基自由基，并且在紫外光照下，增强芬顿反应，实 现光增强的化学动力治疗 ${ }^{[61]}$. 


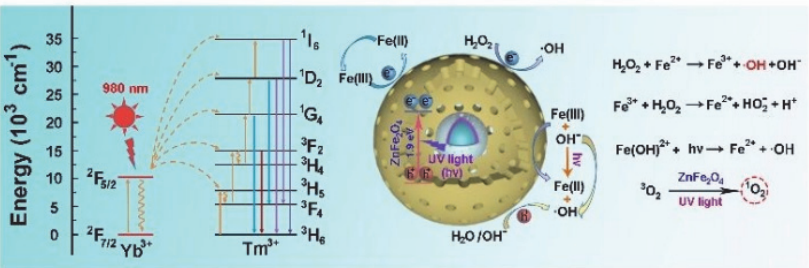

图 $22 \mathrm{ZnFe}_{2} \mathrm{O}_{4}$ 光增强的化学动力治疗的示意图 ${ }^{[1]}$

Figure 22 Schematic illustration of $\mathrm{ZnFe}_{2} \mathrm{O}_{4}$ involved light enhanced chemodynamic therapy ${ }^{[61]}$

Lin 等 ${ }^{[53]}$ 合成了一种新型的杂化上转换纳米材料, 其中 UCNPs 作为内核, 硅层内壳, 介孔 $\mathrm{ZnFe}_{2} \mathrm{O}_{4}$ 壳作为 外壳(如图 23 所示). 进一步其表面修饰多巴胺和 PEG, 增加纳米材料的生物相容性, 并负载 DOX 分子, 构建 协同诊疗体系. 在肿瘤过表达的过氧化氢存在下, 介孔 $\mathrm{ZnFe}_{2} \mathrm{O}_{4}$ 壳发生反应, 生成 ROSs, 并释放抗癌药物 DOX. 并在 UCNPs 发射的紫外光下进一步激发, 生成 ROSs.

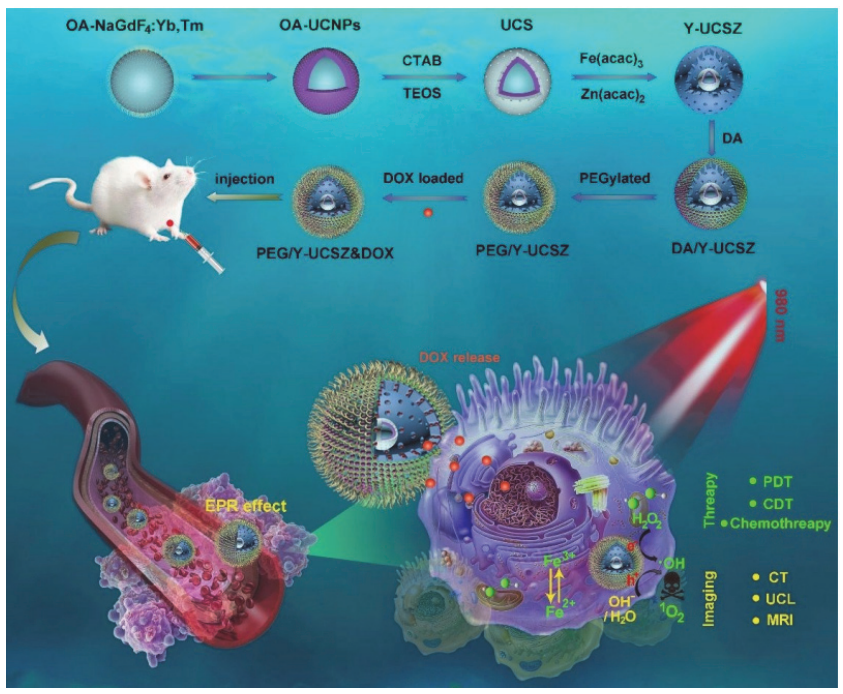

图 $23 \mathrm{ZnFe}_{2} \mathrm{O}_{4}$ 壳修饰的上转换纳米探针用于 PDT, CDT 和化学治疗 示意图 ${ }^{[53]}$

Figure 23 Schematic illustration of UCNPs@ $\mathrm{ZnFe}_{2} \mathrm{O}_{4}$ for PDT, CDT and chemotherapy ${ }^{[53]}$

最近, Yang 等 ${ }^{[69]}$ 基于 $\mathrm{ZnFe}_{2} \mathrm{O}_{4}$ 纳米颗粒也构建了一 种多功能上转换纳米诊疗探针(UCPZ). 如图 24 所示, 该平台由 UCNPs 化学负载铂类前药 Pt(IV), 然后修饰 $\mathrm{ZnFe}_{2} \mathrm{O}_{4}$ 纳米颗粒, 实现光增强的 CDT 和铂类化学药物 参与的药物治疗.

\section{5 总结}

目前, 上转换纳米材料凭借其优异的光学性质和易 修饰的表面结构在肿瘤诊疗一体化方面发挥着重要的 作用. 上转换纳米材料作为光敏剂的激发剂, 通过表面 修饰硅层、聚合物及纳米材料可以构建灵活的上转换光 动力诊疗体系. 基于肿瘤微环境构建刺激响应型上转换

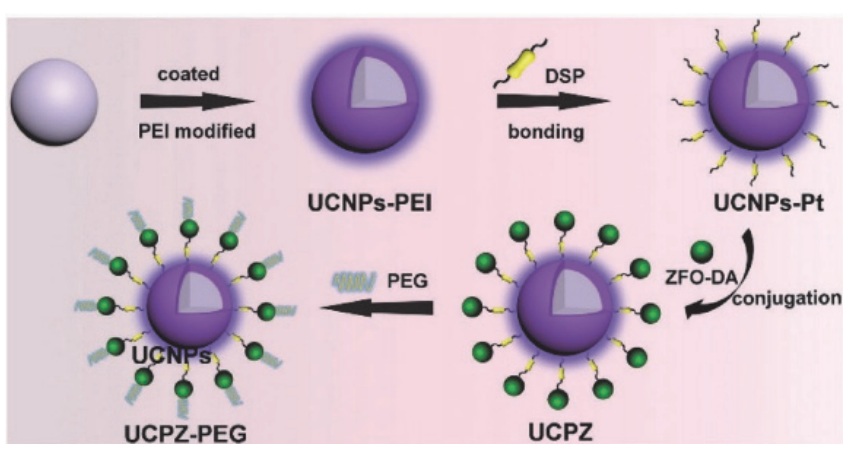

图 24 基于 $\mathrm{ZnFe}_{2} \mathrm{O}_{4}$ 纳米颗粒和铂类前药 $\mathrm{Pt}(\mathrm{IV})$ 构建多功能上转换纳 米诊疗体系 $(\mathrm{UCPZ})^{[69]}$

Figure 24 Development of multi-functional upconversion nanotheranostic system (UCPZ) based on $\mathrm{ZnFe}_{2} \mathrm{O}_{4}$ nanoparticles and platinum (IV) prodrug ${ }^{[69]}$

光动力诊疗体系可以有效地改善诊疗的靶向性，提高光 动力治疗疗效, 减小对周围正常组织的毒副性. 尽管研 究工作者在该方面做出了很多努力, 但仍需要解决一些 关键问题以促进其临床应用转化. 比如大多数报道的 $\mathrm{pH}$ 刺激响应型上转换光动力诊疗体系在 $\mathrm{pH}<6.5$ 条件 下效果显著, 然而肿瘤微环境 $\mathrm{pH}$ 为 $6.5 \sim 6.9$. 因此, 探 索新型的、高度特异性的肿瘤标志物刺激响应型上转换 光动力诊疗体系具有非常重要的意义.

\section{作者简介}

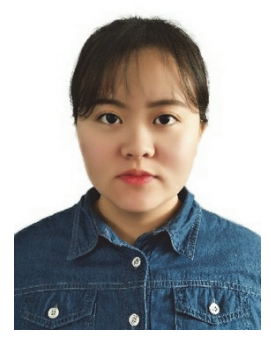

间涛, 自 2019 年起在临沂大学化学化工学院攻读硕士研 究生学位. 她的研究方向涉及上转换功能化纳米探针用于肿 瘤标志物的检测、成像和诊疗一体化.

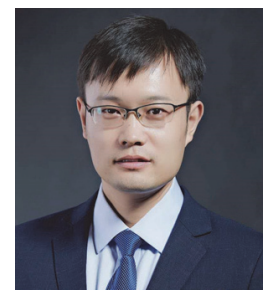

刘振华, 2015 年在东北师范大学获得博士学位, 同年 8 月 加入山东师范大学化学化工与材料科学学院, 现任副教授, 硕士生导师, 曾获吉林省百篇优秀博士论文(2016). 目前其主 要研究方向为有机分子合成方法学及其生物标记应用研究, 近年来在 Nat. Commun., Angew. Chem. Int. Ed., Org. Lett., Anal. Chem., Org. Chem. Front., Sci. China Chem. 等 SCI 期刊发表 $\mathrm{SCI}$ 论文 20 余篇. 承担国家自然科学基金青年项目 1 项, 山东 省自然科学基金 1 项. 


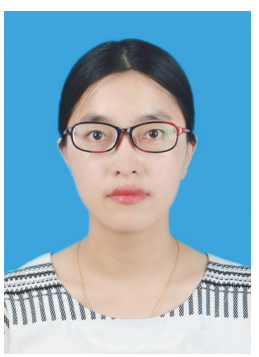

宋昕玥, 2016 年 1 月在中国科学院兰州化学物理研究所获 得博士学位, 同年加入临沂大学生化分析研究所, 现任副教 授, 硕士生导师. 目前其主要研究方向为构建上转换功能化 探针用于肿瘤标志物的检测、多模式成像和诊疗一体化的研 究. 近年来在 Anal. Chem., Trac-Trend. Anal. Chem., Nanoscale, Chem. Commun. 等期刊上发表 SCI 论文 20 余篇, 承担国家自 然科学基金青年项目 1 项, 山东省重点研发计划 1 项, 临沂市 重点研发计划 1 项.

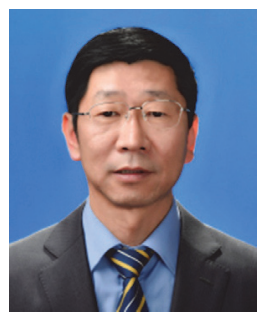

张书圣, 临沂大学教授、博士生导师, 教育部生化分析创 新团队负责人, 国家杰出青年基金获得者、国家百千万人才工 程入选者、国家有突出贡献的中青年专家、泰山学者攀登计 划特聘教授、全国优秀教师、享受国务院政府特殊津贴. 长期 从事单分子检测、细胞成像与肿瘤精准诊疗、新仪器研制等 研究. 相关研究成果发表在 Nat. Protoc., Chem. Soc. Rev., Adv. Funct. Mater, J. Am. Chem. Soc., Angew. Chem., Chem. Sci., Anal. Chem., 中国科学等 SCI 期刊上, 发表论文共计 178 篇, 总引用 7500 次, 他引 6798 次, 授权国家发明专利 25 项. 2019 年受邀在 Springer Nature 出版专著《核酸放大策略在生物传 感、生物成像和生物医药方面的应用》(ISBN 978-981-137044-1). 主持国家自然科学重点项目 1 项、杰出青年项目 1 项、重大仪器专项 2 项、其他国家级课题 6 项, 获得省部级奖 励 6 项. 现任 《Frontiers in Chemistry》副主编; 《分析化学》、 《应用化学》等杂志编委; 中国有机电化学与工业联合会常务 理事; 山东省环境学会副理事长; 中国化工学会、山东省腐蚀 与防护学会理事.

\section{References}

[1] Park, Y. I.; Lee, K. T.; Suh, Y. D.; Hyeon, T. Chem. Soc. Rev. 2015, 44, 1302.

[2] Liu, J. L.; Liu, Y.; Liu, Q.; Li, C. Y.; Sun, L. N.; Li, F. Y. J. Am. Chem. Soc. 2011, 133, 15276.

[3] Kumar, R.; Nyk, M.; Ohulchanskyy, T. Y.; Flask, C. A.; Prasad, P. N. Adv. Funct. Mater. 2009, 19, 853.

[4] Yi, G. S.; Peng, Y. F.; Gao, Z. Q, Chem. Mater. 2011, 23, 2729.

[5] Auzel, F. E. P. IEEE. 1973, 61, 758.

[6] Yi, G. S.; Chow, G. M. Adv. Funct. Mater. 2006, 16, 2324.

[7] Liu, C. H.; Wang, H.; Li, X.; Chen, D. P. J. Mater. Chem. 2009, 19, 3546.

[8] Zijlmans, H. J. M. A. A.; Bonnet, J.; Burton, J.; Kardos, K.; Vail, T.; Niedbala, R. S.; Tanke, H. J. Anal. Biochem. 1999, 267, 30.

[9] Chen, C.; Sun, L. D.; Li, Z. X.; Li, L. L.; Zhang, J.; Zhang, Y. W.; Yan, C. H. Langmuir 2010, 26, 8797.
[10] Wang, Y. F.; Li, L. M.; Xu, T. Y.; Bai, Y. X.; Xie, R.; Yang, P. P. J. Mod. Oncol. 2017, 25, 1489 (in Chinese). (王玉凤, 李隆敏, 许桐 瑛，白玉贤，谢芯，杨飘萍，现代肿瘤医学，2017，25, 1489.)

[11] Pan, Y. S.; Ding, J. Guangzhou Chem. Ind. 2016, 12, 33 (in Chinese). (潘育松, 丁洁, 广州化工, 2016, 12, 33.)

[12] Qian, H. S.; Guo, H, C.; Ho, P. C. L.; Mahendran, R.; Yong, Z. Small 2009, 5, 2285.

[13] Zhang, P.; Steelant, W.; Kumar, M.; Scholfield, M. J. Am. Chem. Soc. 2007, 129, 4526 .

[14] Wang, C.; Tao, H. Q.; Cheng, L.; Liu, Z. Biomaterials 2011, 32, 6145 .

[15] Hamblin, M. R. Dalton Trans. 2018, 47, 8571.

[16] Cheng, F.; Huang, L. T.; Wang, H. H.; Liu, Y. J.; Kandhadi, J.; Wang, H.; Ji, L. N.; Liu, H. Y. Chin. J. Chem. 2017, 35, 86.

[17] Li, M. L.; Peng, X. J. Acta Chim. Sinica 2016, 74, 959 (in Chinese). (李明乐, 彭孝军, 化学学报, 2016, 74, 959.)

[18] Feng, T.; Xue, Z. B.; Yin, J. J.; Jiang, X.; Feng, Y. Q.; Meng, S. X. Chin. J. Org. Chem. 2019, 39, 1891 (in Chinese). (冯朋, 薛中博, 尹娟娟, 蒋旭, 冯亚青, 孟舒献, 有机化学, 2019, 39, 1891.)

[19] Feng, L. L.; He, F.; Liu, B.; Yang, G. X.; Gai, S. L.; Yang, P. P.; Li, C. X.; Dai, Y. L.; Lv, R. C.; Lin, J. Chem. Mater. 2016, $28,7935$.

[20] Chan, M. H.; Chen, C. W.; Lee, I. J.; Chan, Y. C.; Tu, D. T.; Hsiao, M.; Chen, C. H.; Chen, X. Y.; Liu, R. S. Inorg. Chem. 2016, 55, 10267.

[21] Zeng, J. Y.; Wang, X. S.; Zhang, X. Z.; Zhuo, R. X. Acta Chim. Sinica 2019, 77, 1156 (in Chinese). (曾锦跃, 王小双, 张先正, 卓 仁禧, 化学学报, 2019, 77, 1156.)

[22] Li, Y. F.; Di, Z. H.; Gao, J. H.; Cheng, P.; Di, C. Z.; Zhang, G.; Liu, B.; Shi, X. H.; Sun, L. D.; Li, L. L.; Yan, C. H. J. Am. Chem. Soc. 2017, 139, 13804.

[23] Feng, J.; Xu, Z.; Dong, P.; Yu, W. Q.; Liu, F.; Jiang, Q. Y.; Wang, F.; Liu, X. Q. J. Mater. Chem. B 2019, 7, 994.

[24] Yao, J. Z.; Liu, Y.; Wang, J. W.; Jiang, Q.; She, D. J.; Guo, H. S.; Sun, N. R.; Pang, Z. Q.; Deng, C. H.; Yang, W. L.; Shen, S. Biomaterials 2019, 195, 51.

[25] Yue, Z. H.; Hong, T. T.; Song, X. Y.; Wang, Z. H. Chem. Commun. 2018, 54, 10618.

[26] Song, X. Y.; Yue, Z. H.; Hong, T. T.; Wang, Z. H.; Zhang, S. S. Anal. Chem. 2019, 91, 8549.

[27] Liu, K.; Liu, X. M.; Zeng, Q. H.; Zhang, Y. L.; Tu, L. P.; Liu, T.; Kong, X. G.; Wang, Y. H.; Cao, F.; Lambrechts, S. A. G. ACS Nano 2012, 6, 4054.

[28] Kumar, B.; Murali, A.; Bharath, A. B.; Giri, S. Nanotechnology 2019, 30, 315102 .

[29] Kostiv, U.; Patsula, V.; Noculak, A.; Podhorodecki, A.; Vetvicka, D.; Pouckova, P.; Sedlakova, Z.; Horak, D. ChemMedChem 2017, 12, 2066.

[30] Feng, Y. S.; Wu, Y. N.; Zuo, J.; Tu, L. P.; Que, I.; Chang, Y. L.; CruZ, L. J.; Chan, A.; Zhang, H. Biomaterials 2019, $201,33$.

[31] Abouelmagd, S. A.; Hyun, H.; Yeo, Y. Expert Opin. Drug Del. 2014, $11,1601$.

[32] Ju, M. J.; Pang, J. D.; Xu, L. G. Chin. J. Chem. 2017, 35, 1445.

[33] Du, J. Z.; Du, X. J.; Mao, C. Q.; Wang, J. J. Am. Chem. Soc. 2011, 133,17560

[34] Lee, E. S.; Gao, Z. G.; Bae, Y. H. J. Control. Release 2008, 132, 164.

[35] Wang, Y. H.; Song, S. Y.; Zhang, S. T.; Zhang, H. J. Nano Today 2019, $25,38$.

[36] Wang, C.; Cheng, L.; Liu, Y. M.; Wang, X. J.; Ma, X. X.; Deng, Z. Y.; Li, Y. G.; Liu, Z. Adv. Funct. Mater. 2013, 23, 3077.

[37] Wang, S.; Zhang, L.; Dong, C. H.; Su, L.; Wang, H. J.; Chang, J. Chem. Commun. 2015, 51, 406.

[38] Guan, Y.; Lu, H. G.; Li, W.; Zheng, Y. D.; Jiang, Z.; Zou, J. L.; Gao, H. ACS Appl. Mater. Inter. 2017, 9, 26731.

[39] Li, F. Y.; Du, Y.; Liu, J. N.; Sun, H.; Wang, J.; Li, R. Q.; Kim, D.; Hyeon, T.; Ling, D. Adv. Mater. 2018, 30, 1802808.

[40] Juarez, A. V.; Sosa, L. d. V.; Paul, A. L. D.; Costa, A. P.; Farina, M.; Leal, R. B.; Torres, A. I.; Pons, P. J. Photoch. Photobio. B 2015, 153, 445.

[41] Liu, X. M.; Fan, Z. Q.; Zhang, L.; Jin, Z.; Yan, D. M.; Zhang, Y. L.; Li, X. D.; Tu, L. P.; Xue, B.; Chang, Y. L.; Zhang, H.; Kong, X. G. Biomaterials 2017, 144, 73.

[42] Oltersdorf, T.; Elmore, S. W.; Shoemaker, A. R.; Armstrong, R. C; Augeri, D. J.; Belli, B. A.; Bruncko, M.; Deckwerth, T. L.; Dinges, J.; Hajduk, P. J.; Joseph, M. K.; Kitada, S.; Korsmeyer, S. J.; Kunzer, A. R.; Letai, A.; Li, C.; Mitten, M. J.; Nettesheim, D. G.; Ng, S. C.; 
Nimmer, P. M.; O'Connor, J. M.; Oleksijew, A.; Petros, A. M.; Reed, J. C.; Shen, W.; Tahir, S. K.; Thompson, C. B.; Tomaselli, K. J.; Wang, B.; Wendt, M. D.; Zhang, H. C.; Fesik, S. W.; Rosenberg, S. H. Nature 2005, 435, 677.

[43] Liu, S. K.; Li, W. T.; Dong S. M.; Gai, S. L; Dong, Y. S.; Yang, D.; Dai, Y. L.; He, F.; Yang, P. P. ACS Appl. Mater. Inter. 2019, 11, 47659.

[44] Yu, Z. Z.; Ge, Y. G.; Sun, Q. Q.; Pan, W.; Wan, X. Y.; Li, N.; Tang, B. Chem. Sci. 2018, 9, 3563 .

[45] Lee, G. Y.; Qian, W. P.; Wang, L. Y.; Wang, Y. A.; Staley, C. A.; Satpathy, M.; Nie, S. M.; Mao, H.; Yang, L. ACS Nano 2013, 7, 2078.

[46] Li, Y. Y.; Zhang, X. B.; Zhang, Y.; Zhang, Y.; He, Y. L.; Liu, Y.; Ju, H. X. ACS Appl. Mater. Inter. 2020, 12, 19313.

[47] Ai, X. Z.; Ho, C. J. H.; Aw, J.; Attia, A. B. E.; Mu, J.; Wang, Y.; Wang, X.; Wang, Y.; Liu, X. G.; Chen, H. B.; Gao, M. Y.; Chen, X. Y.; Yeow, E. K. L.; Liu, G.; Olivo, M.; Xing, B. G. Nat. Commun. 2016, 7, 10432.

[48] Dickinson, B. C.; Chang, C. J. Nat. Chem. Biol. 2011, 7, 504.

[49] Cai, H. J.; Shen, T. T.; Zhang, J.; Shan, C. F.; Jia, J. G.; Li, X.; Liu, W. S.; Tang, Y. J. Mater. Chem. B 2017, 5, 2390.

[50] Liang, S.; Sun, C. Q.; Yang, P. P.; Ma, P. A.; Huang, S. S.; Cheng, Z. Y.; Yu, X. F.; Lin, J. Biomaterials 2020, 240, 119850.

[51] Gu, T. X.; Cheng, L.; Gong, F.; Xu, J.; Li, X.; Han, G. R.; Liu, Z. ACS Appl. Mater. Inter. 2018, $10,15494$.

[52] Lin, J.; Ding, B. B.; Shao, S.; Xiao, H. H; Sun, C. Q.; Cai, X. C; Jiang, F.; Zhao, X. Y.; Ma, P. A. Nanoscale 2019, 11, 14654.

[53] Dong, S. M.; Xu, J. T.; Jia, T.; Xu, M. S.; Zhong, C. N.; Yang, G. X.; Li, J. R.; Yang, D.; He, F.; Gai, S. L.; Yang, P. P.; Lin, J. Chem. Sci. 2019, $10,4259$.

[54] Jia, T.; Xu, J. T.; Dong, S. M.; He, F.; Zhong, C. N.; Yang, G. X.; Bi, H. T.; Xu, M. S.; Hu, Y. K.; Yang, D.; Yang, P. P.; Lin, J. Chem. Sci. 2019, 10, 8618.

[55] Xu, J. T.; Han, W.; Yang, P. P.; Jia, T.; Dong, S. M.; Bi, H. T.; Gulzar, A.; Yang, D.; Gai, S. L.; He, F.; Lin, J.; Li, C. X. Adv. Funct. Mater.
2018, 28, 1803804.

[56] Zhao, L.; Ge, X. Q.; Zhao, H. J.; Shi, L. Y.; Capobianco, J.; Jin, D. Y.; Sun, L. N. ACS Applied Nano Materials 2018, 1, 1648.

[57] Yuan, J.; Cen, Y.; Kong, X. J.; Wu, S.; Liu, C. L.; Yu, R. Q.; Chu, X. ACS Appl. Mater. Inter. 2015, 7, 10548.

[58] Ai, X. Z.; Hu, M.; Wang, Z. M.; Lyu, L.; Zhang, W. M.; Li, J.; Yang, H. H.; Lin, J.; Xing, B. G. Bioconjugate Chem. 2018, 29, 928.

[59] Sun, Q. Q.; He, F.; Sum, C. Q.; Wang, X. X.; Li, C. X.; Xu, J. T.; Yang, D.; Bi, H. T.; Gia, S. L.; Yang, P. P. ACS Appl. Mater. Inter. 2018, 10, 33901.

[60] Deng, R. R.; Xie, X. J.; Vendrell, M.; Chang, Y. T.; Liu, X. G. J. Am. Chem. Soc. 2011, 133, 20168.

[61] Fan, W. P.; Bu, W. B.; Shen, B.; He Q. J.; Cui, Z. W.; Liu, Y. Y.; Zheng, X. P.; Zhao, K. L.; Shi, J. L. Adv. Mater. 2015, $27,4155$.

[62] Feng, L. L.; He, F.; Dai, Y. L.; Gai, S. L.; Zhong, C. N.; Li, C. X.; Yang, P. P. Biomater. Sci-UK. 2017, 5, 2456.

[63] Gu, T. X.; Cheng, L.; Gong, F.; Xu, J.; Li, X.; Liu, Z. ACS Appl. Mater. Inter. 2018, 10, 15494.

[64] Xu, J. T.; He, F.; Cheng, Z. Y.; Lv, R. C.; Dai, Y. L.; Gulzar, A.; Liu, B.; Bi, H. T.; Yang, D.; Gai, S. L.; Yang, P. P.; Lin, J. Chem. Mater. 2017, 29, 7615.

[65] Lv, R. C.; Wang, Y. X.; Liu, J.; Feng, M.; Yang, F.; Jiang, X.; Tian, J. ACS Biomater. Sci. Eng. 2019, 5, 3100.

[66] Zhang, C.; Chen, W. H.; Liu, L. H.; Qiu, W. X.; Yu, W. Y.; Zhang, X. Z. Adv. Funct. Mater. 2017, 27, 1700626.

[67] Jiang, W.; Zhang, C.; Ahmed, A.; Zhao, Y. L.; Deng, Y.; Ding, Y.; Cai, J. F.; Hu, Y. Adv. Healthc. Mater. 2019, 8, 1900972.

[68] Hu, P.; Wu, T.; Fan, W. P.; Chen, L.; Liu, Y. Y.; Ni, D. L.; Bu, W. B.; Shi, J. L. Biomaterials 2017, 141, 86.

[69] Bi, H. T.; Dai, Y. L.; Yang, P. P.; Xu, J. T.; Yang, D.; Gai, S. L.; He, F.; Liu, B.; Zhong, C. N.; An, G. H.; Lin, J. Small 2018, 14, 1703809

(Cheng, B.) 